\title{
贝壳杉烷型二萜合成进展
}

\author{
杜明军 $a$ 雷晓光*,a,b \\ $\left({ }^{a}\right.$ 天津大学药物科学与技术学院 天津 300072$)$ \\ $\left({ }^{b}\right.$ 北京大学化学与分子工程学院 北京 100871)
}

\begin{abstract}
摘要 贝壳杉烷型二萜, 特别是对映-贝壳杉烷型二萜是萜类天然产物家族中的主要组成部分. 这类分子通常表现出 抗菌、抗肿瘤、抗症、抗病毒等多种重要生物活性. 在分子结构上, 这类四环二萜分子可以通过分子内氧化反应, 切断 反应以及重排反应, 展现出复杂多样性. 因此, 对这类分子的全合成研究始终是国内外合成化学家的重点研究方向. 根据这类分子的不同结构类型，分类阐述了近期国内外学者对此类分子的全合成研究.

关键词 二萜; 对映-贝壳杉烷; 全合成
\end{abstract}

\section{Advanced in the Synthesis of Kaurane Diterpenoids}

\author{
$\mathrm{Du}$, Mingjun ${ }^{a} \quad$ Lei, Xiaoguang ${ }^{*, a, b}$ \\ ( ${ }^{a}$ Shoool of Pharmaceutical Science and Technology, Tianjin University, Tianjin 300072) \\ ( ${ }^{b}$ College of Chemistry and Molecular Engineering, Peking University, Beijing 100871)
}

\begin{abstract}
Kaurane, especially ent-kaurane diterpenoids are integral parts of terpenoid natural products, and possess various bioactivities, including antibacterial, antitumor, antimalarial and antiviral activities. Additionally, as a result of intramolecular oxidations, cleavages and rearrangements, the tetracyclic ent-kaurane also shows attractive structural diversity. Hence, the total syntheses of ent-kauranes have evoked a great deal of interest in the synthetic community. This review presents the recent advances in the synthesis of ent-kaurane and kauranediterpenoids.
\end{abstract}

Keywords diterpenoids; ent-kaurane; total synthesis

二萜类天然产物是萜类天然产物家族中重要组成 成员. 2006 年, 孙汉董等 ${ }^{[1]}$ 对分离自唇形科香茶菜属植 物中的二萜类分子进行了综述, 文中主要对二萜类分子 的分类和生物活性进行了阐述. 二萜类分子具有多种多 样的生物学活性, 这些生物学活性主要包括抗菌活

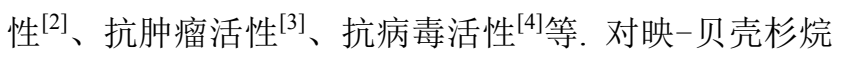
是二萜类分子中的重要组成成员, 其生物合成途径是通 过香叶基香叶基焦磷酸 (geranylgeranyl diphosphate, GGPP)的酶催化环化反应实现的 ${ }^{[5]}$.

植物中的四环二萜类的生物合成最早是在植物激 素赤霉素(Gibberellins)的研究过程中逐渐被探索的. 目 前人们普遍接受的生源合成途径是一个由 GGPP 开始 的酶催化的分步环化过程. 首先, GGPP 通过柯巴合成 酶(copalyl synthase)的环化作用形成双环柯巴焦磷酸 (copalyl diphosphate, CPP); CPP 在贝壳杉烯合酶 (kaurene synthase B)的作用的催化下通过碳正离子环
化过程形成叔碳碳正离子中间体. 随后, 双键与叔碳 碳正离子加成, 形成仲碳正离子的贝叶烷型中间体, 该中间体进一步转化形成对映二萜分子的前体一一 对映贝壳杉烯(ent-kaurene) (Scheme 1).

这类分子从结构上主要可以分为 C-20 位未被氧化 的贝壳杉烷(如 phyllocladene)、C-20 位被氧化的贝壳杉 烷(如 neotripterifordin)、6,7-位断裂的对映-贝壳杉烷(如 enmein 和 15-desoxyeffusin)、8,9-位断裂的对映-贝壳杉 烷(如 rabdoumbrosanin)、8,15-位或 15,16-位断裂的对 映一贝壳杉烷(如 rubescensins U 和 rubescensin S)、7,20位环化的对映-贝壳杉烷 (如 xerophilusin F)、对映-贝壳 杉烷二聚体(如 isodopharicin F)、其他类型的对映-贝壳 杉烷(如 maoecrystal V)等多种类别. 由于这类分子在生 物活性和结构上的多样性, 对这类分子的全合成研究引 起了国内外合成化学家的广泛关注(图 1).

\footnotetext{
*E-mail: xglei@pku.edu.cn

Received September 21, 2015; revised October 22, 2015; published online October 26, 2015.
} 

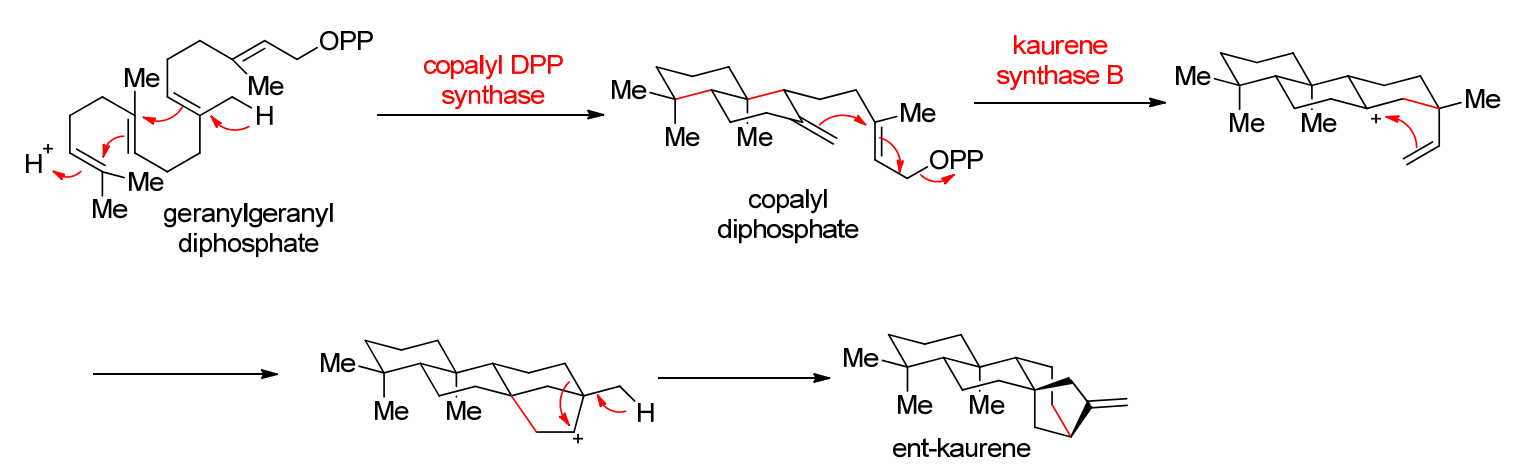

图式 1 对映贝壳杉烯的生物合成途径

Scheme 1 Biosynthesis route of ent-kaurene

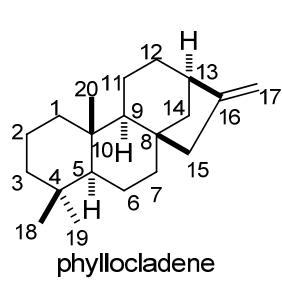

(1)

enmein

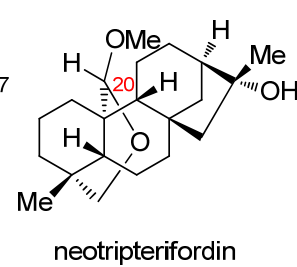

neotripterifordin

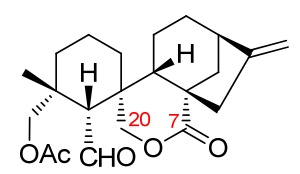

15-desoxyeffusin

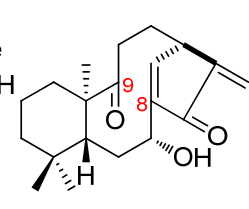

rabdoumbrosanin

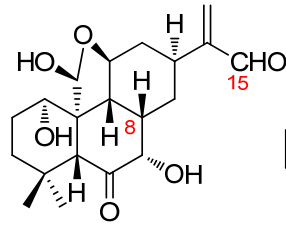

rubescensins $U$

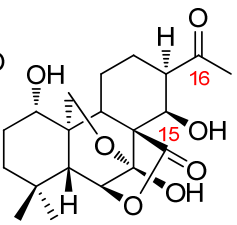

rubescensin $\mathrm{S}$

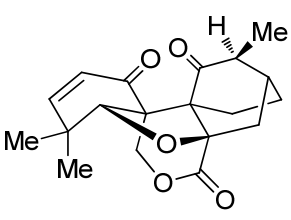

maoecrystal V

图 1 多种结构的对映-贝壳杉

Figure 1 Diversity on the structures of ent-kauranes

本文将会对贝壳杉烷型, 特别是对映-贝壳杉烷型 二萜分子的相关合成工作进行综述. 由于目前分离得到 的 7,20-位环化的对映-贝壳杉烷分子只有 xerophilusin F, 而且还没有对其的全合成报道, 所以本文综述的主要类 别包括: (1) C-20 位未被氧化的贝壳杉烷, (2) C-20 位被 氧化的贝壳杉烷，(3) 6,7-位断裂的对映-贝壳杉烷，(4) 8,9 -位断裂的对映一贝壳杉烷, (5) 8,15-位或 15,16-位断裂 的对映-贝壳杉烷, (6) 其他类型的对映贝壳杉烷.

\section{C-20 位未被氧化的贝壳杉烷}

C-20 位未被氧化的贝壳杉烷约占已知的二萜类天 然产物的三分之一, 这一类分子具有以下特点: (1) C-20 位总是一个孤立的甲基，(2) C-15 位通常被酮羰基或羟 基官能团化, (3)只有 C-5 位和 C-9 位从来不被官能团化.

\subsection{Turner 组对( \pm )-phyllocladene 的合成}

1966 年, Turner 小组 ${ }^{[6]}$ 完成了对 $( \pm)$-phyllocladene 的立体专一性的全合成, 这一工作在二萜的立体合理性 合成史上具有里程碑式的意义. 他们以 Cornforth-
Robinson 酮 1 为起始原料, 经过双甲基化反应、羰基还 原反应和催化加氢等反应合成化合物 $\mathbf{2}$, 再通过 Wolff-Kishner 还原反应脱除 C-3 位羟基和去芳构化反应 得到环酮化合物 3. 接下来, 在 C-8 位引入烯丙基侧链 时, 他们首先在 $\mathrm{C}-13$ 位引入一个呋喃醛取代基, 烯丙基 化反应发生在阻碍较小的一侧形成化合物 $\mathbf{4}$, 然后, 臭 氧解和 Dieckmann 环化反应实现 C-8 位手性翻转. 化合 物 6 经过 Reformatsky 加成反应和 $\beta$-消除反应生成烯烃 混合物 7, 环酮结构 8 通过选择性的加氢反应和 Claisen 缩合反应而获得, 再经过羰基 $\alpha$ 位甲酰化反应和羰基还 原反应等得到烯醛 $\mathbf{9}$, 最后经过 Wolff-Kishner 条件得到 (土)-phyllocladene. 在此合成策略中, 通过臭氧解和 Claisen 缩合反应实现 C-8 位四级中心的构建, 并通过 Claisen 缩合反应实现对 D 环的构建(Scheme 2).

\subsection{Ireland 组对( \pm )-phllocladene 的形式全合成}

Ireland 小组 ${ }^{[7]}$ 于 1966 年完成了 $( \pm)$-phyllocladene 的形式全合成. 他们报道了一个相对于 Turner 的合成更 

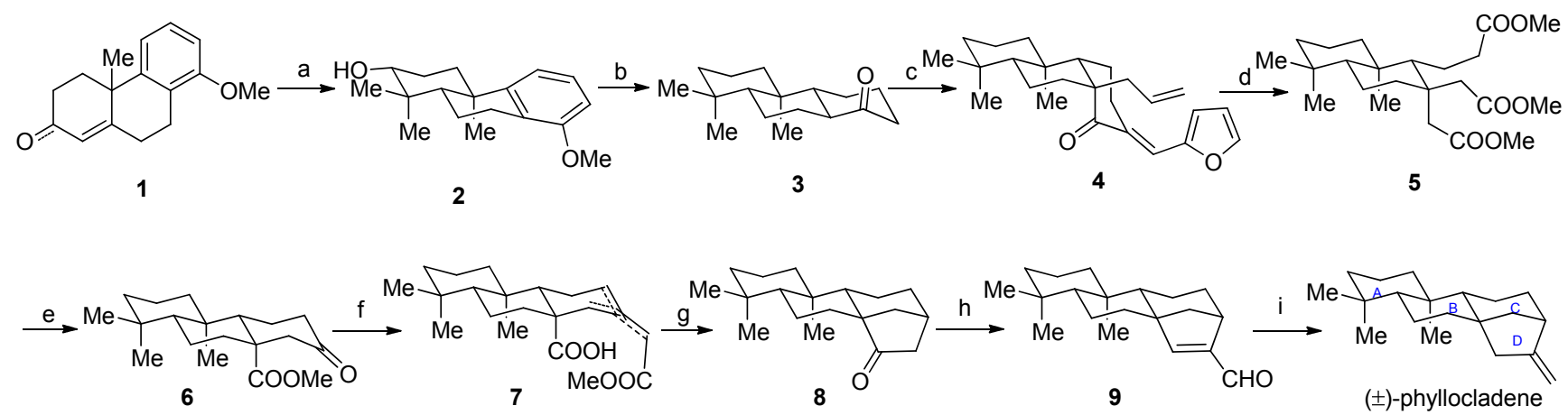

Reagents and conditions: (a) (1) $t$-BuOK/t-BuOH, Mel, 65\%; (2) $\mathrm{LAH}, \mathrm{Et}_{2} \mathrm{O}, 67 \%$; (3) $\mathrm{H}_{2}, \mathrm{Pd} / \mathrm{C}, \mathrm{AcOH}, 81 \%$. (b) (1) $\mathrm{CrO}_{3}$; (2) $\mathrm{HI}$; (3) $\mathrm{N}_{2} \mathrm{H}_{4} /$ $\mathrm{KOH}$; (4) $\mathrm{H}_{2}$, Raney Ni; (5) $\mathrm{CrO}_{3}$. (c) (1) $\mathrm{HCO}-\mathrm{C}_{4} \mathrm{H}_{3} \mathrm{O} / \mathrm{KOH}, \mathrm{MeOH}, 91 \%$; (2) $\mathrm{CH}_{2}=\mathrm{CHCH}_{2} \mathrm{Br} / \mathrm{t}-\mathrm{BuOK}$, benzene, 87\%. (d) (1) $\mathrm{O}_{3}$, ethyl acetate; (2) $\mathrm{CrO}_{3}, \mathrm{AcOH}$; (3) $\mathrm{CH}_{2} \mathrm{~N}_{2}$. (e) (1) $t-\mathrm{BuOK} / t-\mathrm{BuOH}$; (2) $\mathrm{HCl}$ (con.), $\mathrm{AcOH}$; (3) $\mathrm{CH}_{2} \mathrm{~N}_{2}, 34 \%$. (f) (1) $\mathrm{CH}_{3} \mathrm{CO}_{2} \mathrm{CH}_{2} \mathrm{Br}, \mathrm{Zn}$, benzene, $57 \%$; (2) $\mathrm{Na}$ $\mathrm{OMe} / \mathrm{MeOH}$. (g) (1) $\mathrm{PtO}_{2}, \mathrm{AcOH}$; (2) $\mathrm{NaOH}, \mathrm{MeOH} / \mathrm{H}_{2} \mathrm{O}$; (3) $\mathrm{Ba}(\mathrm{OH})_{2}$, heat, 50\%. (h) (1) $\mathrm{NaH}, \mathrm{HCOOEt}$, benzene; (2) 2-ethyl-2-methyl-1,3-dioxolane, $p$ - $\mathrm{TsOH}, 33 \%$; (3) $\mathrm{LAH}, \mathrm{Et}_{2} \mathrm{O}$, then $\mathrm{HCl}, 54 \%$. (i) $\mathrm{N}_{2} \mathrm{H}_{4} / \mathrm{KOH}$

图式 2 Turner 小组的( \pm )-phyllocladene 全合成工作

Scheme 2 Turner's synthesis of $( \pm)$-phyllocladene

为经济的合成路线. 在这条路线中, 从烯酮 10 这一在合 成中经常使用的中间体出发, 经过一步甲基化反应和一 步羰基脱除反应合成化合物 11, 实现 $\mathrm{A} / \mathrm{B}$ 环相对立体构 型的构建, 进一步发生 Birch 还原反应获得烯酮 12. 接 下来的氢化还原可以生成化合物 13A 和 13B 两个具有 不同手性的醇, 比例为 $4: 1$. 经过 Claisen 重排反应和 氧化反应将化合物 14 转化为化合物 15 , 再将 $\mathrm{C}$ 环中的 环内双键切断, 经过 Claisen 缩合反应得到 Turner 合成 过程中使用的中间体 6. 之后使用 Turner 的方法经过相 应转化得到 $( \pm)$-phyllocladene. 这一合成路线的亮点在 于通过分子内 Claisen 重排反应构建 C-8 位的四级碳中 心. 虽然得到相反的相对立体构型, 但可以通过臭氧解 和 Claisen 缩合反应实现手性的翻转(Scheme 3).

\subsection{Fetizon 组对( \pm )-phyllocladene 的合成}

Fetizon 小组 ${ }^{[8]}$ 于 1975 年通过一条简短的路线完成 了对( \pm )-phyllocladene 的合成. 他们从很常用的三环环 酮 16 出发, 经过与联烯发生光催化的 $[2+2]$ 环加成反 应，实现立体选择性和区域选择性地合成四环二萜化合 物 17 , 在酸的催化下, 化合物 17 重排为化合物 18 , 虽然 这步反应只有 $50 \%$ 的收率, 但大大缩短了合成路线. D 环上的羰基可以经过 Wolff-Kishner 还原反应除去, 得到 异扁枝烯 19. 最后经过烯丙基溴化-还原反应得到目标 分子 $( \pm)$-phyllocladene. 这一工作的最大新意在于通过 $[2+2]$ 环加成反应引入 C-8 位的四级碳中心, 开创了这 一方法在 D 环构建上使用的先河 (Scheme 4).

\subsection{Fetizon 组对( \pm )-hibaene 的合成}

通过使用酮中间体 12, Fetizon 小组 ${ }^{[9]}$ 于 1978 年完成 了对( \pm )-hibaene 的全合成. 化合物 $\mathbf{1 2}$ 与乙酸乙烯基酯
通过光催化的环加成反应得到区域和立体选择性的乙 酸环丁基酯 20. 中间体化合物 21 经过羰基的 1,2-加成 和脱水反应转化为化合物 22 . 接下来, 化合物 22 与甲 酸反应一个月得到双甲酸酯 23 , 再经过进一步还原得 到二醇化合物 24. 选择性地氧化六元环上的羟基得到 酮醇化合物 25 , 酮醇化合物经过顺式消除反应和 Wolff-Kishner 还原反应得到目标分子 $( \pm)$-hibaene (Scheme 5).

\subsection{Ireland 组对( \pm )-hibaene 的合成}

Ireland 小组 ${ }^{[10]}$ 也曾于 1965 年完成了对 $( \pm)$-hibaene 的合成. 从已知的化合物 $\mathbf{2 7}$ 出发, 通过与亚乙基 Wittig 试剂加成, 得到烯烃化合物 28, 并进一步转化为甲基酮 29. 化合物 29 结构中的乙缩醛水解后经过 Aldol 环化反 应、乙酰化反应和 Beckmann 重排反应转化为化合物 $\mathbf{3 0}$. 化合物 30 经过重氮化合物中间体 $\mathbf{3 1}$ 在桥头位置引入乙 酰氧基得到化合物 32. 接下来选择性地将次级乙酰氧 基转化为亚甲基并在酸作用下发生重排反应得到酮 34, 最后经过嗍氢化还原反应和消除反应获得天然产物 $( \pm)$-hibaene. 这一工作将 Aldol 环化反应应用到 D 环的 构建中, 具有很强的原创性(Scheme 6).

\subsection{Ireland 组对( \pm )-kaurene 的合成}

Ireland 小组 ${ }^{[11]}$ 也于 1962 年完成了对 $( \pm)$-kaurene 的 全合成工作. 他从已知的化合物 $\mathbf{3 5}$ 出发, 首先对醛基进 行保护得到乙缩醛 36, 经过硼氢化氧化反应得到酮 $\mathbf{3 7}$ 和 38, 比例为 $1: 1.6$. 具有 kaurene 骨架结构的二酮 39 可以由化合物 37 经过酸催化的关环反应及氧化反应而 获得，经过选择性的亚甲基化反应及 Wolff-Kishner 还原 反应得到目标天然产物 $( \pm)$-kaurene. 这一合成工作对 

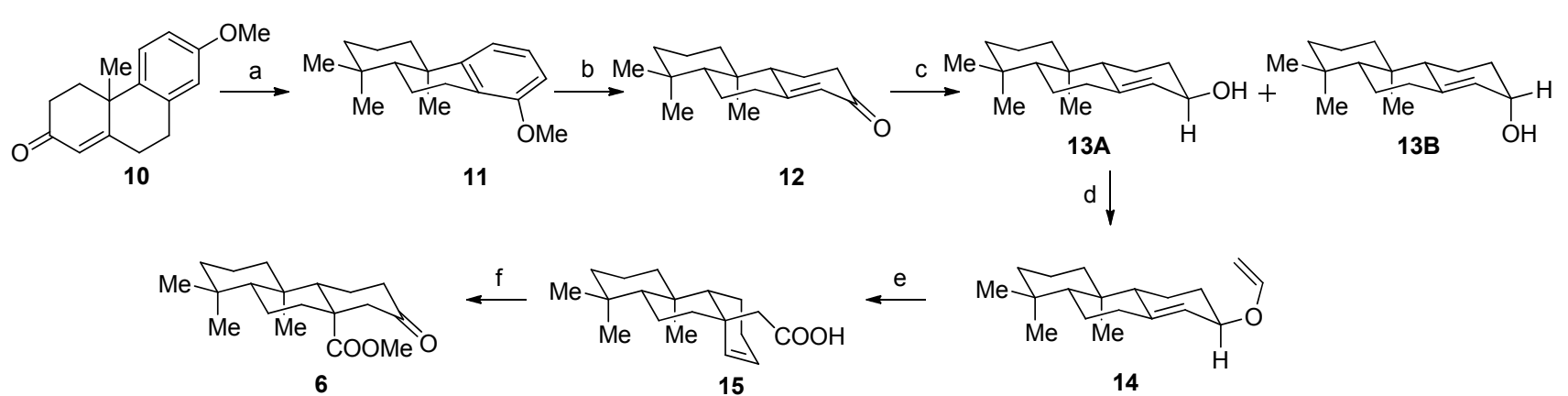

Reagents and conditions: (a) (1) $t$-BuOK/t-BuOH, Mel, 75\%; (2) $\mathrm{HSCH}_{2} \mathrm{CH}_{2} \mathrm{SH}, \mathrm{BF}_{3} \cdot \mathrm{Et}_{2} \mathrm{O}$; (3) Ni(R), $\mathrm{EtOH}, 90 \%$. (b) (1) $\mathrm{Li} / \mathrm{NH}_{3}$; (2) $\mathrm{H}_{3} \mathrm{O}^{+}$, $\mathrm{EtOH}, 90 \%$. (c) $\mathrm{LAH}, 76 \%$ of $13 \mathrm{~A}$ and $20 \%$ of 13B. (d) $\mathrm{CH}_{2}=\mathrm{CHOC}_{2} \mathrm{H}_{5}, \mathrm{Hg}(\mathrm{OAc})_{2}, 90 \%$. (e) (1) heat, then $\mathrm{Ag}_{2} \mathrm{O}, 76 \%$. (f) (1) $\mathrm{KMnO}_{4} / \mathrm{HIO}_{4}$; (2) $\mathrm{SOCl}_{2}$; (3) $\mathrm{CH}_{3} \mathrm{OH}$, pyridine; (4) $\mathrm{NaOMe}, \mathrm{CH}_{2} \mathrm{~N}_{2}, 19 \%$

图式 3 Ireland 小组的 $( \pm)$-phyllocladene 形式全合成工作

Scheme 3 Ireland's formal total synthesis of $( \pm)$-phyllocladene
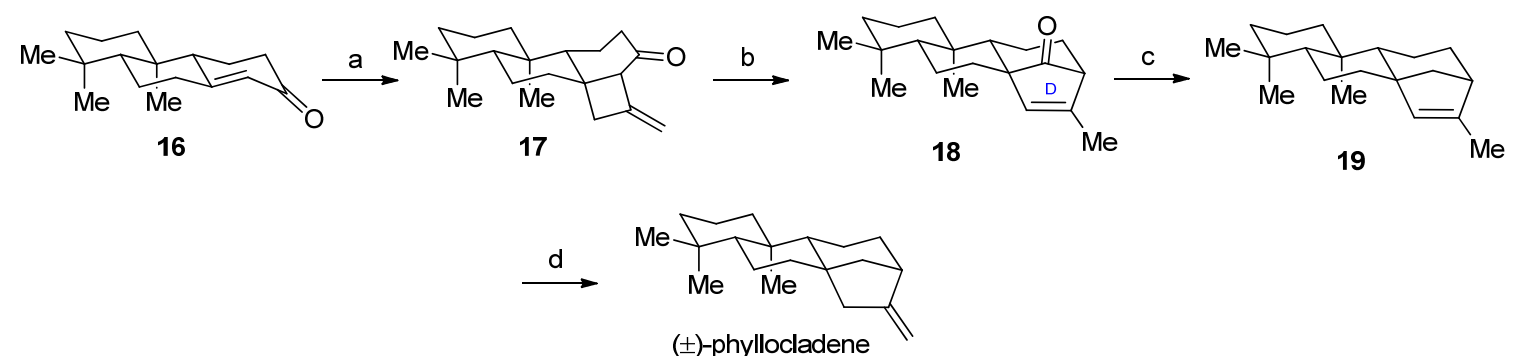

Reagents and conditions: (a) allene, hv. (b) $p$-TsOH, $50 \%$. (c) $\mathrm{N}_{2} \mathrm{H}_{4} / \mathrm{KOH}$. (d) (1) NBS; (2) $\mathrm{Zn} / \mathrm{HOAc}$

图式 4 Fetizon 小组的 $( \pm)$-phyllocladene 全合成工作

Scheme 4 Fetizon's synthesis of $( \pm)$-phyllocladene

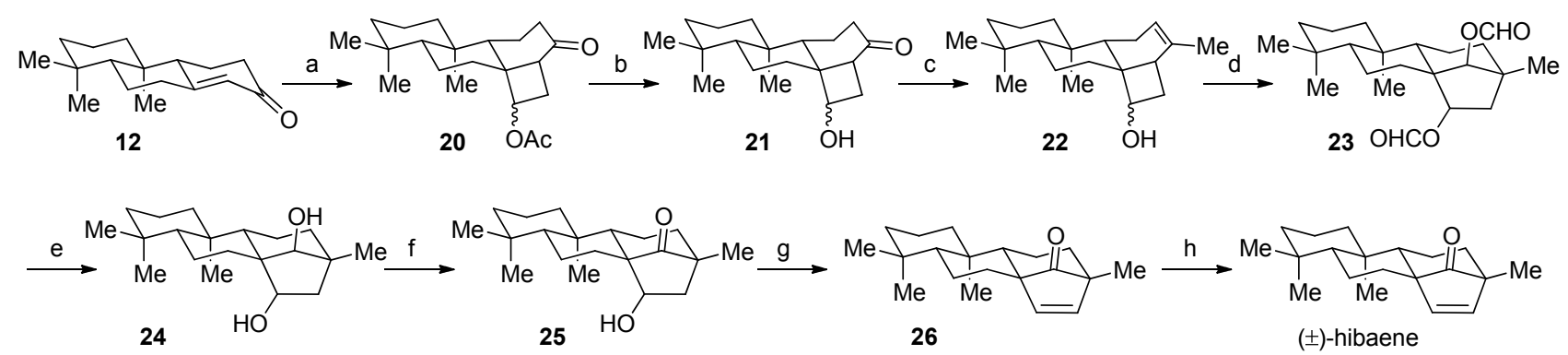

Reagents and conditions: (a) $\mathrm{CH}_{2}=\mathrm{CHOAc}, \mathrm{DCM}, \mathrm{h} v, 23 \%$. (b) (1) $\mathrm{HOCH}_{2} \mathrm{CH}_{2} \mathrm{OH} / p-\mathrm{TsOH}$, benzene; (2) LAH, Et ${ }_{2} \mathrm{O}$; (3) $3 \mathrm{~mol} / \mathrm{L} \mathrm{HCl}, \mathrm{DCM}$. (c) (1) $\mathrm{CH}_{3} \mathrm{Li}, \mathrm{Et}_{2} \mathrm{O}$; (2) $\mathrm{HCO}_{2} \mathrm{H}$. (d) $\mathrm{HCO}_{2} \mathrm{H}, 30$ d. (e) $\mathrm{LAH}, \mathrm{Et}_{2} \mathrm{O}$. (f) $\mathrm{Ag}_{2} \mathrm{CO}_{3}$, benzene. (g) $p$-TosOcoCl, benzene, then $200{ }^{\circ} \mathrm{C}$. (h) $\mathrm{N}_{2} \mathrm{H}_{4} \cdot \mathrm{H}_{2} \mathrm{O} /$ $\mathrm{KOH}$, diethylene glycol

图 5 Fetizon 小组的 $( \pm)$-hibaene 合成工作

Scheme 5 Fetizon's synthesis of $( \pm)$-hibaene

D 环的构建也是采用 aldol 反应(Scheme 7).

\subsection{Masamune 组对( \pm )-kaurene 的合成}

Masamune 小组 ${ }^{[12]}$ 也于 1964 年完成了对 $( \pm)-$ kaurene 的全合成工作. 该路线从具有二环结构的酸 41 出发, 经过羰基溴化物 $\mathbf{4 2}$ 和苯酚结构化合物 $\mathbf{4 3}$ 等中间 体, 进而发生环化去芳构化反应生成环化的二烯酮结构 化合物 44, 再经还原后进行区域选择性的插羰反应及 酯化反应转化为 $\alpha$-羰基酯 45 . 在合成四环烯酮 46 过程
中使用了 Robinson 环化反应. 接下来, 经过甲基化反 应、催化加氢反应得到二酮结构化合物 47. 选择性地保 护环戊酮上羰基并发生 Wolff-Kishner 还原反应获得酯 类化合物 48 后，进一步将甲酯基团转化为甲基得到 49, 经过与 Ireland 相同的策略实现接下来的转化得到天然 产物(土)-kaurene. 这一策略中, 先通过具有 $\mathrm{B} / \mathrm{C}$ 环的原 料先构建 $\mathrm{D}$ 环，最后实现对 $\mathrm{A}$ 环的构建，与以往的合成 策略具有很大的不同(Scheme 8). 

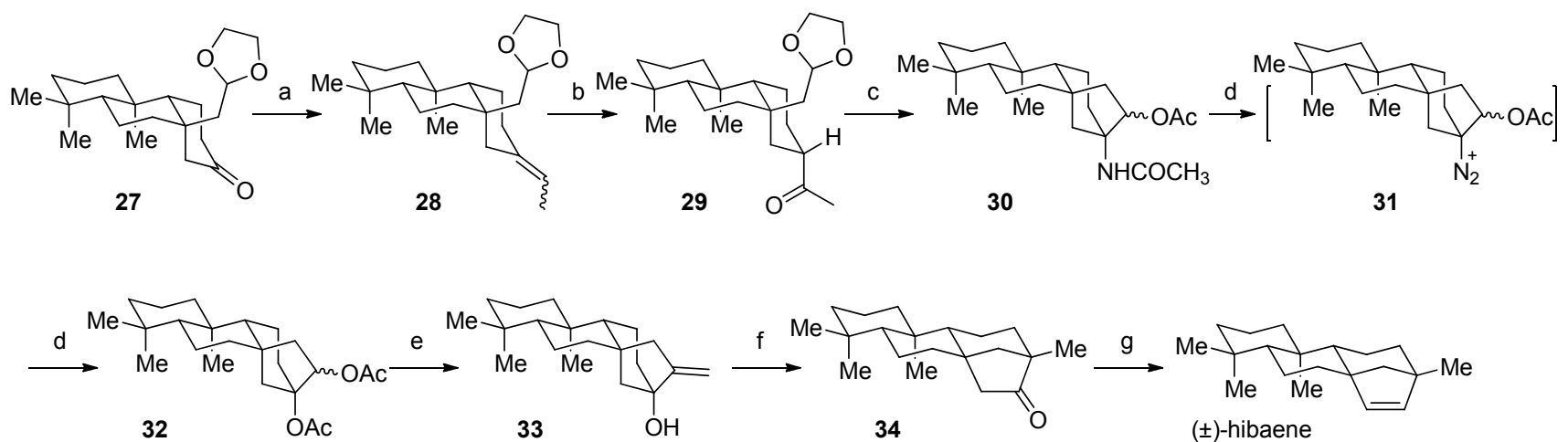

Reagents and conditions: (a) $\mathrm{CH}_{3} \mathrm{CH}=\mathrm{PPh}_{3}, 98 \%$. (b) $\mathrm{B}_{2} \mathrm{H}_{6}, \mathrm{H}_{2} \mathrm{O}_{2}, 80 \%$. (c) (1) $\mathrm{HCl}$, acetone; (2) $\mathrm{Ac}{ }_{2} \mathrm{O}$; (3) $\mathrm{H}_{2} \mathrm{NOH}, p$ - $\mathrm{TsCl}$, heat, $82 \%$ overall. (d) $\mathrm{N}_{2} \mathrm{O}_{2}, \mathrm{HOAc} / \mathrm{NaOAc}$, dioxane $/ \mathrm{H}_{2} \mathrm{O}, 96 \%$. (e) (1) $\mathrm{OH}^{-}$, then $\mathrm{CrO}_{3}$; (3) $\mathrm{Ph}_{3} \mathrm{P}=\mathrm{CH}_{2}$, THF/t-BuOH, $74 \%$ overall. (f) $3 \mathrm{~mol} / \mathrm{L} \mathrm{HCl} / \mathrm{MeOH}, 60 \%$. (g) (1) $\mathrm{NaBH}_{4}$; (2) $p$ - TsCl, collidine, heat, $30 \%$

图式 6 Ireland 小组的(土)-hibaene 合成工作

Scheme 6 Ireland's synthesis of ( \pm )-hibaene

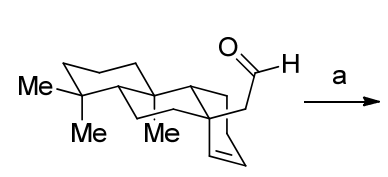

35

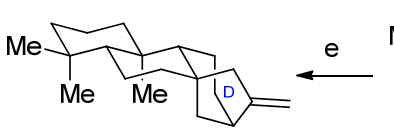

(土)-kaurene

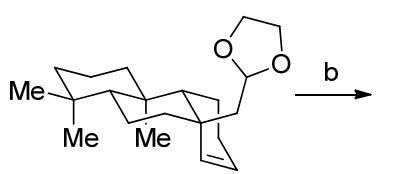

36

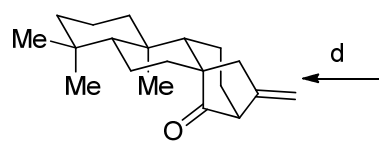

40

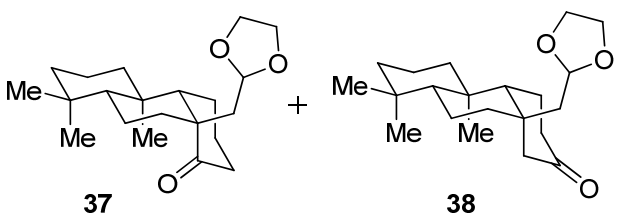

$c \downarrow$

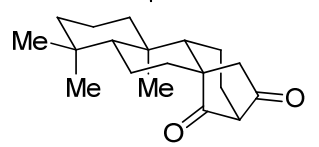

39

Reagents and conditions: (a) $\mathrm{HOCH}_{2} \mathrm{CH}_{2} \mathrm{OH}, p$-TsOH. (b) (1) $\mathrm{BH}_{3} / \mathrm{THF}$; (2) $\mathrm{H}_{2} \mathrm{O}_{2}, 26 \%$ of 37 and $42 \%$ of 38. (c) (1) $\mathrm{H}_{3} \mathrm{O}^{+}$; (2) $\mathrm{CrO}_{3}, 90 \%$. (d) $\mathrm{Ph}_{3} \mathrm{P}=\mathrm{CH}_{2}, 81 \%$. (e) $\mathrm{N}_{2} \mathrm{H}_{4} / \mathrm{KOH}, 65 \%$

图式 7 Ireland 小组的(土)-kaurene 合成工作

Scheme 7 Ireland's synthesis of $( \pm)$-kaurene

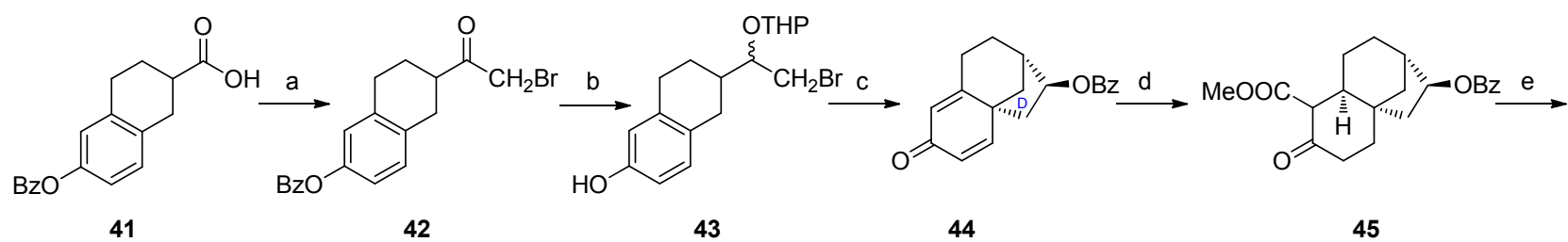

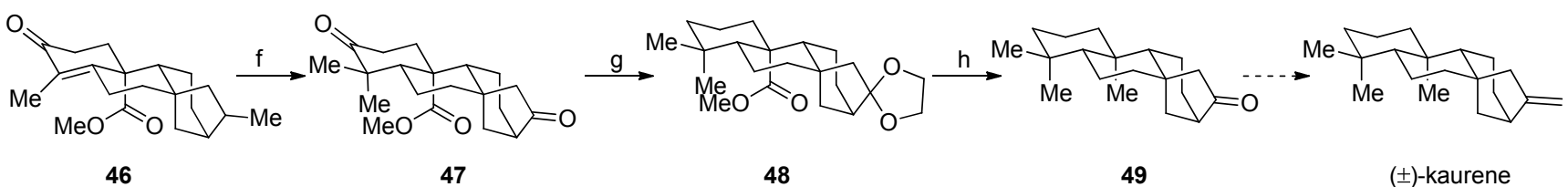

Reagents and conditions: (a) (1) $(\mathrm{COCl})_{2}$; (2) $\mathrm{CH}_{2} \mathrm{~N}_{2}$; (3) $\mathrm{HBr}$. (b) (1) $\mathrm{NaBH}_{4}$; (2) $\mathrm{DHP} / \mathrm{H}^{+}$; (3) $\mathrm{H}_{2}$, Pd/C. (c) (1) t-BuOK; (2) $\mathrm{H}_{3} \mathrm{O}^{+}$; (3) $\mathrm{PhCOCl}$, the overall yield from 41 is $30 \%$. (d) (1) $\mathrm{H}_{2}, \mathrm{Pd} / \mathrm{CaCO}_{3}$; (2) $\mathrm{CO}_{2}, \mathrm{Ph}_{3} \mathrm{CNa}$; (3) $\mathrm{CH}_{2} \mathrm{~N}_{2}$. (e) (1) pent-1-en-3-one/OH $\mathrm{OH}^{-}$( (2) $\mathrm{DHP} / \mathrm{H}^{+}$. (f) (1) $\mathrm{CH}_{3} \mathrm{l}$, $t$-BuOK; (2) $\mathrm{H}_{3} \mathrm{O}^{+}$; (3) $\mathrm{CrO}_{3}$. (g) (1) $\mathrm{H}_{2}, \mathrm{Pd} / \mathrm{C}, 60 \%$; (2) $\mathrm{HOCH}_{2} \mathrm{CH}_{2} \mathrm{OH} / \mathrm{H}^{+}$; (3) $\mathrm{N}_{2} \mathrm{H}_{4} / \mathrm{KOH}$. (h) (1) $\mathrm{LAH}$; (2) $\mathrm{CrO}_{3} / \mathrm{Pyridine}$; (3) $\mathrm{N}_{2} \mathrm{H}_{4} / \mathrm{KOH}$

图式 8 Masamune 小组的 $( \pm)$-kaurene 合成工作

Scheme 8 Masamune's synthesis of $( \pm)$-kaurene

1.8 Monti 组对 $( \pm)$-stachenone 的合成

1979 年, Monti 小组 ${ }^{[13]}$ 通过以具有 C/D 二环结构 $\mathbf{5 0}$
为起始原料, 逐步构建 $\mathrm{B}$ 环、 $\mathrm{A}$ 环的策略实现了对 (土)stachenone 的全合成, 这一策略与以往的合成策略具有 很大的区别. 原料 50 经过格氏加成反应和酸催化的重 
排反应转化为具有 C,D 二环结构的二酮 $\mathbf{5 2}$. 在碱的作用 下，二酮结构会发生环化反应引入 B 环. 烯醇硅醚结构 的化合物 54 经过 Michael 加成和 aldol 环化反应构建出 A 环合成具有四环骨架的酮 55, 最后还原烯醇结构并发 生羰基 $\alpha$ 位甲基化反应, 得到( \pm )-stachenone (Scheme 9).

\subsection{Mori 组对( \pm )-steviol methyl ester 的合成}

Mori 小组 ${ }^{[14]}$ 最早于 1966 年实现对 (土)-steviol methyl ester 的全合成, 他们以 Barltrop 和 Day 小组合成的 三环烯酮酯 $\mathbf{5 6}^{[15]}$ 为起始原料, 经过一系列转化包括 Claisen 重排、乙缩醛的形成、硼氢化氧化反应等, 得到 酮乙缩醛 57, 再经过乙缩醛结构的水解、 aldol 缩合反 应、氧化反应等得到桥环二酮 $\mathbf{5 8} . \mathrm{Zn} / \mathrm{HCl}$ 还原化合物 $\mathbf{5 8}$
生成具有三元环的中间体 59, 三元环开环后生成[3,2,1] 桥环化合物 60 和 61 . 其中 60 经过 Wittig 反应转化为 (土)-steviol methyl ester. 虽然在文章中没有提及 overbred 中间体这一概念，但该合成是比较早的使用 overbred 中间体的工作(Scheme 10).

\subsection{Cook 组对( $( \pm)$-steviol 的形式合成}

Cook 和他的同事 ${ }^{[16]}$ 实现了 $( \pm)$-steviol 的形式合成. 他们以化合物 62 为起始原料, 这一三环结构可以由 kaurenoic acid 降解而获得. 62 经 $\mathrm{Na} / \mathrm{NH}_{3}$ 还原偶联转化 为二羟基酸结构并经过选择性氧化得到酮醇 63 . 保护 的 63 经过 Wittig 亚甲基化反应和去保护合成目标分子 (士)-steviol (Scheme 11).

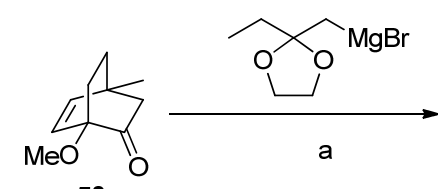

50

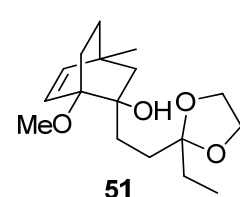

51

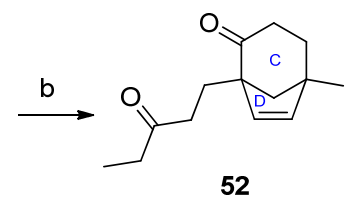

52

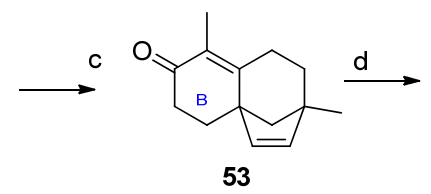

53<smiles>COC1=C(C)[C@H]2CC[C@]3(C)C=C[C@@]2(CC1)C3</smiles>

54

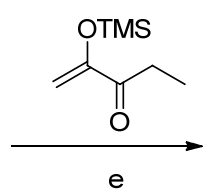

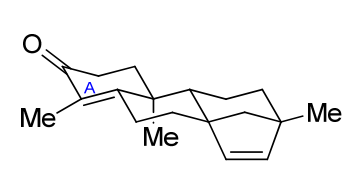

55

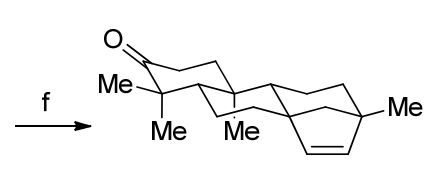

(土)-stachenone

Reagents and conditions: (a) RMgBr, $57 \%$. (b) p-TsOH, AcOH. (c) $\mathrm{NaOMe}, \mathrm{MeOH}, 90 \%$ in two steps. (d) (1) $\mathrm{Na} / \mathrm{NH}_{3}$; (2) $\mathrm{TMSCl}$. (e) $\mathrm{CH}_{3} \mathrm{Li}$, DME, $65 \%$ (recover yield). (f) $\mathrm{Li} / \mathrm{NH}_{3}$, then $\mathrm{CH}_{3} \mathrm{l}$, THF, $47 \%$

图式 9 Monti 小组的 $( \pm)$-stachenone 合成工作

Scheme 9 Monti's synthesis of $( \pm)$-stachenone
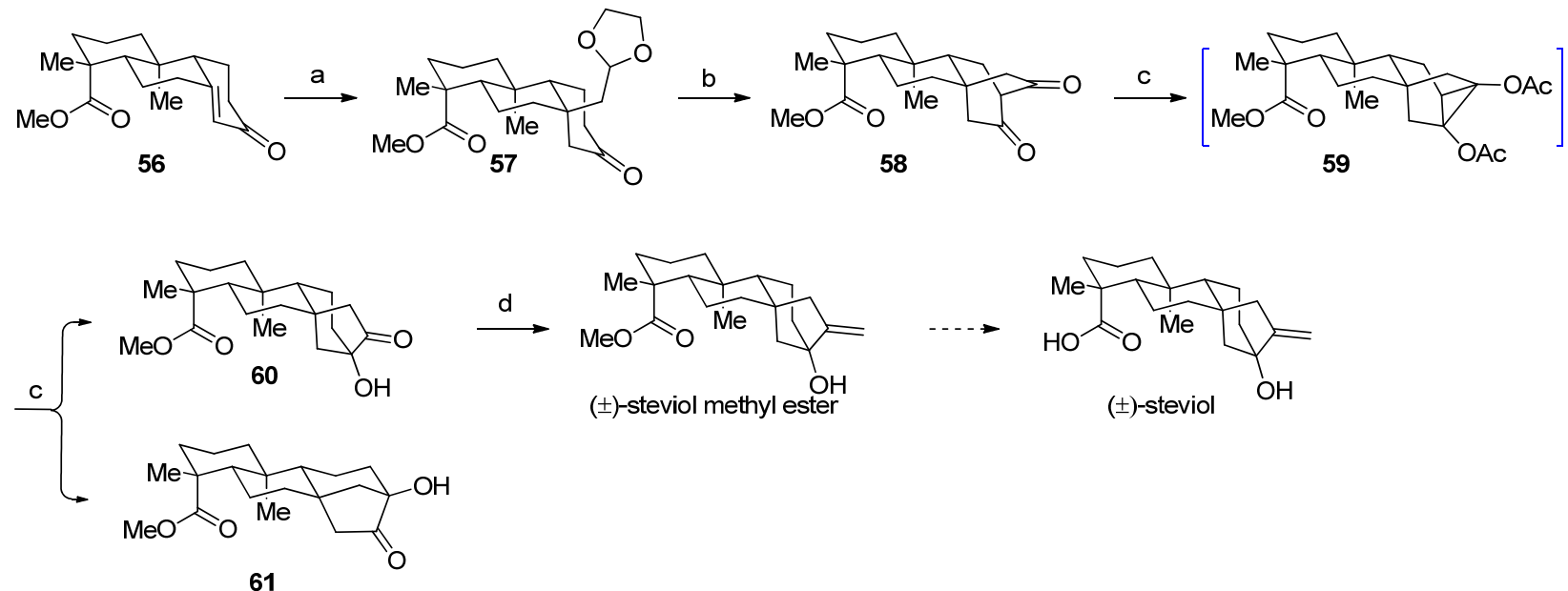

Reagents and conditions: (a) (1) $\mathrm{LiAl}(t-\mathrm{BuO})_{3} \mathrm{H}$; (2) $\mathrm{CH}_{2}=\mathrm{CHOC}_{2} \mathrm{H}_{5}, \mathrm{Hg}(\mathrm{OAc})_{2}$; (3) heat; (4) $\mathrm{HOCH}_{2} \mathrm{CH}_{2} \mathrm{OH}, p$ - $\mathrm{TsOH}$; (5) $\mathrm{B}_{2} \mathrm{H}_{6}, \mathrm{H}_{2} \mathrm{O}_{2}, \mathrm{NaOH}$; (6) $\mathrm{CrO}_{3}$. (b) (1) $\mathrm{H}_{3} \mathrm{O}^{+}$; (2) $\mathrm{CrO}_{3}$. (c) $\mathrm{Zn} / \mathrm{HCl}$. (d) $\mathrm{Ph}_{3} \mathrm{P}=\mathrm{CH}_{2}$

图式 10 Mori 小组的 $( \pm)$-steviol methyl ester 合成工作

Scheme 10 Mori's synthesis of $( \pm)$-steviol methyl ester 


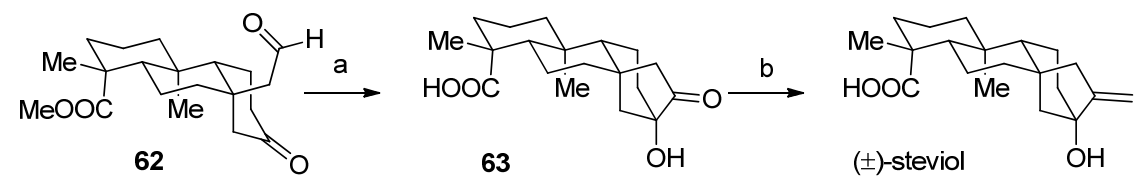

Reagents and conditions: (a) (1) $\mathrm{Na} / \mathrm{NH}_{3}$; (2) $\mathrm{CrO}_{3} /$ Pyridine. (b) (1) $\mathrm{TMSCl}$; (2) $\mathrm{Ph}_{3} \mathrm{P}=\mathrm{CH}_{2}$; (3) $\mathrm{H}_{3} \mathrm{O}^{+}$

图式 11 Cook 小组的 $( \pm)$-steviol 形式合成工作

Scheme 11 Cook's formal synthesis of $( \pm)$-steviol

1.11 Ziegler 和 Kloek 组对 $( \pm)$-steviol methyl ester 和 ( \pm )-isosteviol methyl ester 的合成

Ziegler 和 Kloek 组于 1977 年完成了对( \pm )-steviol methyl Ester 和 $( \pm)$-isosteviol methyl ester 的全合成 ${ }^{[17]}$. 他们从 Hagemann 酯 64 出发, 经过羰基 $\alpha$ 位烷基化反应 和环化反应转化为已知的三环环酮 65 , 通过 Wittig 反应 转化而来的烯醇醚中间体再经过水解反应、烷基化反应 和氧化反应合成芳香三环羧酸 66, 再经过 Birch 还原、 脱羰基作用及甲酯化反应转化为去芳构化的三环羧酸 甲酯 67, 再用臭氧降解并经过烯胺化水解反应合成烯 醛 68, 在光环化条件下与丙二烯发生环化反应并发生 还原磺酰化得到化合物 69, 再经过溶剂解作用得到 (土)-steviol methyl ester, 甲磺酸化的 steviol methyl ester
70 在盐酸作用下发生重排反应得到( \pm )-isosteviol methyl ester (Scheme 12).

\subsection{Snider 组对 $( \pm)$-isosteviol 的合成}

使用 $\mathrm{Mn}(\mathrm{OAc})_{3} \cdot 2 \mathrm{H}_{2} \mathrm{O}$ 引发的自由基环化反应的方 法合成五元到八元环系已经有报道 ${ }^{[18]} .1998$ 年, Snider 等 ${ }^{\left[{ }^{[9]}\right.}$ 以 $\mathrm{Mn}(\mathrm{OAc})_{3} \cdot 2 \mathrm{H}_{2} \mathrm{O}$ 和 $\mathrm{Cu}(\mathrm{OAc})_{2}$ 为氧化剂通过氧化 环化反应完成了对 $( \pm)$-isosteviol 的全合成. 氧化自由基 环化反应前体 71 在 $\mathrm{Mn}(\mathrm{OAc})_{2} \cdot 2 \mathrm{H}_{2} \mathrm{O}$ 和 $\mathrm{Cu}(\mathrm{OAc})_{2}$ 作用 下发生自由基环化反应转化为四环骨架结构化合物 72 . 接下来, 还原 3 位羰基并在四氧化锇和高碘酸钠氧化条 件下氧化切断亚甲基得到 $\mathrm{D}$ 环环酮结构化合物 73. 化 合物 73 消除 3 位着基后催化加氢后，再经过氢化铝锂还 原和 Jones 氧化得到目标产物( \pm )-isosteviol (Scheme 13).

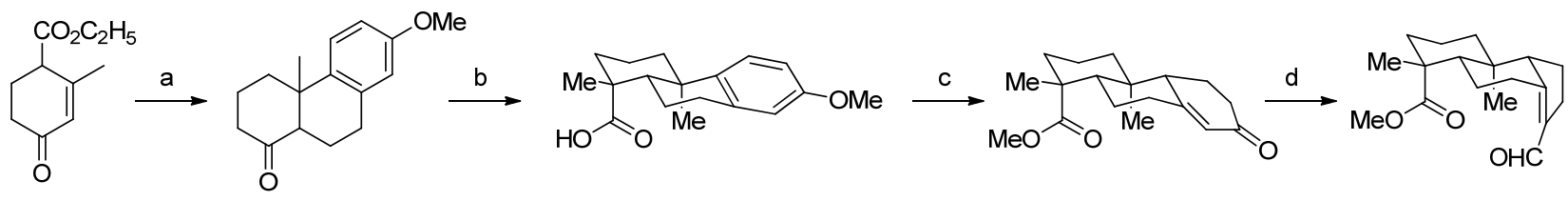

64

65
66

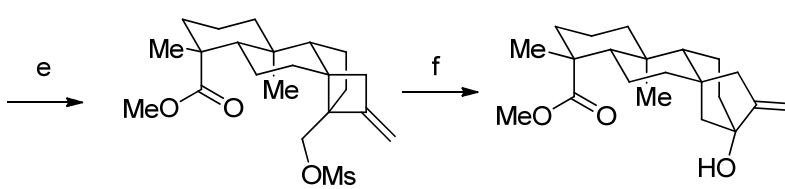

69

$( \pm)$-steviol methyl ester

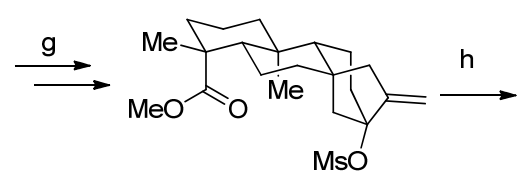

70
68

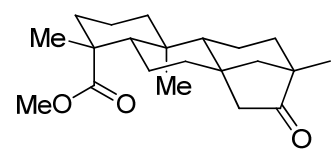

( \pm )-isosteviol methyl ester

Reagents and conditions: (a) (1) $t$-BuOK/t-BuOH, toluene, then $m$-methoxyphenethyl alcohol; (2) $\mathrm{H}_{2} \mathrm{SO}_{4}$, EtOH, $66 \%$ in tow steps; $(3) \mathrm{P}_{2} \mathrm{O}_{5}$, $\mathrm{MeSO}_{3} \mathrm{H}, 50 \%$. (b) (1) NaH, DMSO, $\mathrm{Ph}_{3} \mathrm{P}=\mathrm{CHOMe}, 88 \%$; (2) $\mathrm{HCl}$ (con.), THF, 95\%; (3) $t$-BuOK, Mel, $t$-BuOK, 65\%. (4) CrO 3 , acetone, $89 \%$. (c) (1) $\mathrm{Li} / \mathrm{NH}_{3}$, (2) $\mathrm{AcOH}$, then $\left(\mathrm{HSCH}_{2}\right)_{2} / \mathrm{BF}_{3}, 78 \%$; (3) $\mathrm{Li} / \mathrm{NH}_{3}, \mathrm{THF}, 87 \%$. (d) (1) $\mathrm{CH}_{2} \mathrm{~N}_{2}, \mathrm{O}_{3}, \mathrm{DCM} / \mathrm{MeOH}, \mathrm{Me} 2 \mathrm{~S}$, then $10 \% \mathrm{HCl}, 89 \%$; (2) $\mathrm{pyr}-$ rolidine, $\mathrm{HOAc} / \mathrm{H}_{2} \mathrm{O}, 40 \%$. (e) Allene, hv, 42\%. (f) (1) $\mathrm{NaBH}_{4}, \mathrm{EtOH}, 90 \%$; (2) $\mathrm{MeSO}_{2} \mathrm{Cl}$, pyridine, 93\%; (3) $\mathrm{H}_{2} \mathrm{O} / a c e t o n e, ~ 2,6-l u t i d i d n e .21 \%$. (g) $\mathrm{MsCl}$. (h) $20 \% \mathrm{HCl}, \mathrm{MeOH}, 55 \%$

图式 12 Ziegler 和 Kloek 小组的( \pm )-steviol methyl ester 和( \pm )-isosteviol methyl ester 合成工作

Scheme 12 Ziegler and Kloek's synthesis of ( \pm )-steviol methyl ester and ( \pm )-isosteviol methyl ester<smiles>C=CC/C(=C\CCCC(=O)CC(=O)OCC)CCCC(=O)OCC</smiles>

71

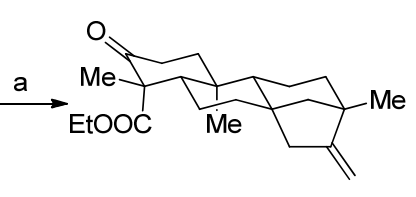

72

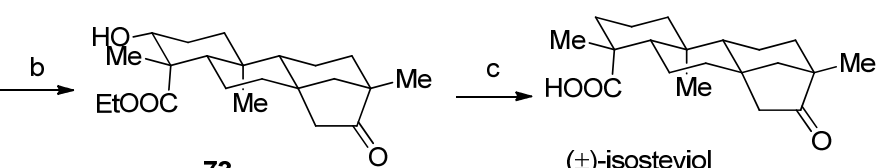

73

Reagents and conditions: (a) (1) $\mathrm{Mn}(\mathrm{OAc})_{2}, \mathrm{Cu}(\mathrm{OAc})_{2}, \mathrm{MeOH}, 35 \%$. (b) (1) $\mathrm{NaBH}_{4}, 99 \%$; (2) $\mathrm{OsO}_{4}, \mathrm{NalO}_{4}, 93 \%$. (c) (1) $\mathrm{DEAD}, \mathrm{Ph}_{3} \mathrm{P}$, toluene, then $\mathrm{H}_{2}$, Pd/C, 79\%; (2) LAH, 98\%; (3) Jones oxidation, $72 \%$

图式 13 Snider 小组的 $( \pm)$-isosteviol 合成工作

Scheme 13 Snider's synthesis of $( \pm)$-isosteviol 


\subsection{Baran 组对( \pm )-steviol 和( \pm )-isosteviol 的合成}

Baran 小组 ${ }^{[20]}$ 于 2013 年完成了对 $( \pm)$-steviol 和 ( \pm )-isosteviol 的全合成工作. 在对[3.2.1]双环体系的构 建路线中, 主要依靠两个 overbred 中间体 ${ }^{[21]}$ 可控的断裂 来实现的. Overbred 这一概念由 Hoffmann 与 2009 年正 式确立, 所谓 overbred 中间体就是在合成设计中设计出 来的具有一个或多个附加的碳-碳键必须在后续反应中 切断的中间体.

该合成工作第一个挑战是立体和区域选择性的合 成三环体系 76. 已有的方法如自由基介导的环化反应、 $\mathrm{C}-\mathrm{H}$ 活化反应、末端环氧引发的环化反应等不能很好 地完成这一任务. 于是, Baran 课题组设计了一个特殊的 环化前体 75, 对这一前体的设计出于以下几点考虑: (1) 环化反应应由 Lewis 酸引发得到正确的 para 区域选择 性; (2)环氧化物是内部的而非末端的; (3) Z 式的立体选 择性.

由于对引入四级碳中心的多种尝试(包括： $\mathrm{Cu}, \mathrm{In}$,
Sn 介导的 1,4-加成反应、Sakurai 和 Keck 烯丙基化反应、 分子内 sigmatropic 重排反应等)以失败告终, 他们战略 性的通过 $[2+2]$ 光环化反应得到 Overbred 环丁烷中间体 78 引入四级碳中心

以 74 为起始原料, 经过开环氧环、环氧化手性翻转 等多步转化得到环化前体 $\mathbf{7 5}$, 在三氯化铁作用下发生 环化反应, 高效地获得三环体系 76. 76 经必要的转化后 发生 Birch 还原并与丙二烯发生[2+2]光环加成反应生 成 C-8 位为四级碳的环丁烷 78 后, 发生一锅反应构建 [2.2.2]双环系统 79. 79 发生还原环丙烷化反应后得到的 环丙二醇结构可以通过 C(12)-C(13)切断或 C(12)-C(16) 切断反应分别得到 81 和 82 . 其中 82 可以经过 Wittig 反 应和氧化反应转化为 $( \pm)$-steviol. ( \pm )-Steviol 可以在溴 化氢作用下发生重排反应转化为 $( \pm)$-isosteviol. 82 也可 以先在溴化氢作用下发生重排反应后再发生氧化反应 得到 $( \pm)$-isosteviol (Scheme 14).

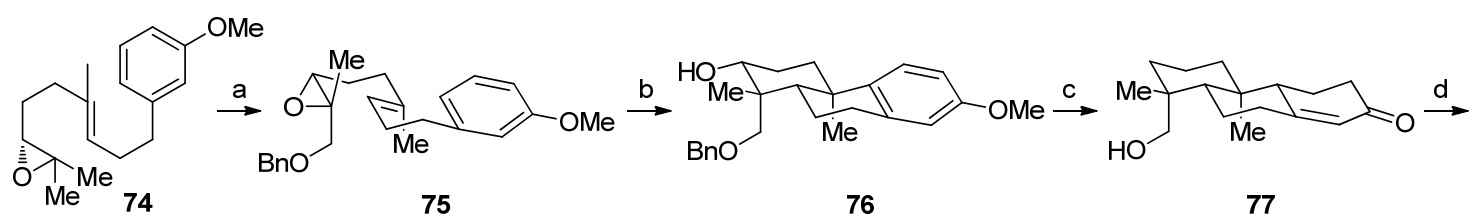

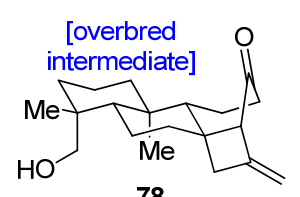

78
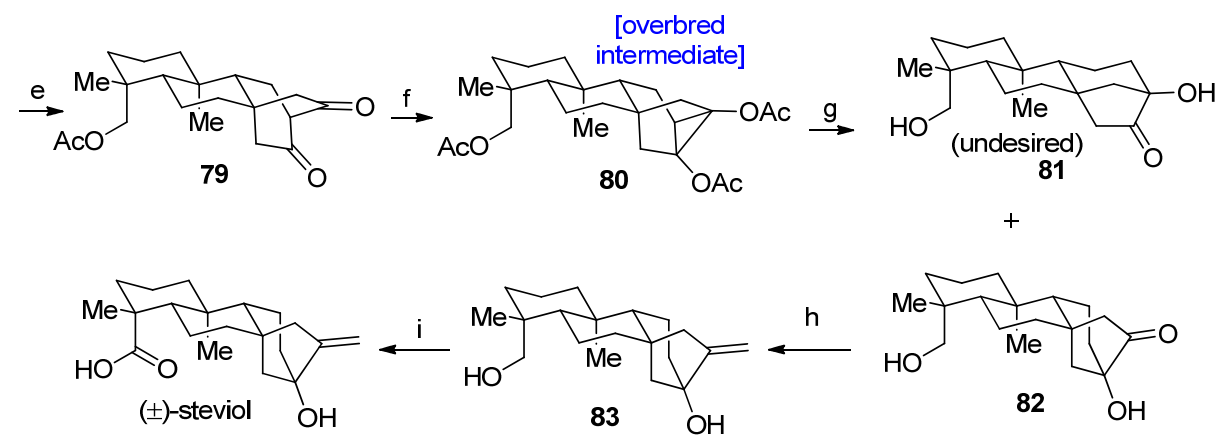

83

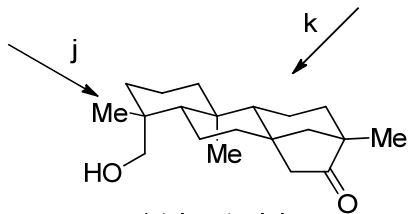

$( \pm)$-isostevio
$\mathrm{OH}$

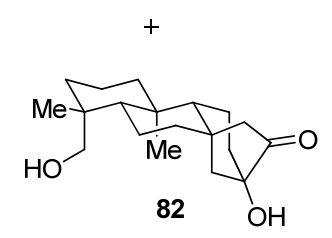

Reagents and conditions: (a) (1) $\mathrm{LiNEt}_{2}$; (2) [VO(acac) $)_{2}$, $t \mathrm{BuOOH}$; (3) $\mathrm{Ph}_{3} \mathrm{P}, \mathrm{CBr}_{4}$; (4) $\mathrm{BnOH}, t-\mathrm{BuONa}, 51 \%$ overall. (b) $\mathrm{FeCl}$ (2 equiv.), $\mathrm{CH}_{2} \mathrm{Cl}_{2}$, r.t., $3 \mathrm{~h}, 52 \%$. (c) (1) DEAD (5 equiv), $\mathrm{PPh}_{3}$ (5 equiv.), THF, $70^{\circ} \mathrm{C}, 5 \mathrm{~h}$; (2) $\mathrm{H}_{2}$, $\mathrm{Pd} / \mathrm{C}\left(10 \mathrm{wt} \%\right.$; $10 \mathrm{~mol} \%$ ), EtOAc, r.t., $7 \mathrm{~h}$; (3) Li/ $/ \mathrm{NH}_{3}$, then $\mathrm{HCl}, 67 \%$ overall. (d) allene, $\mathrm{CH}_{2} \mathrm{Cl}_{2}$, r.t., $450 \mathrm{~W} \mathrm{Hg}$ lamp, pyrex, $12 \mathrm{~h}, 82 \%$. (e) $\mathrm{O}_{3}, \mathrm{MeOH},-78^{\circ} \mathrm{C}, 5 \mathrm{~min} ; \mathrm{Me}_{2} \mathrm{~S}$, r.t., $30 \mathrm{~min} ; \mathrm{AcOH} / \mathrm{PPA}(9$ : 1), $110{ }^{\circ} \mathrm{C}, 12 \mathrm{~h}, 62 \%$. (f) $\mathrm{HCl}$ (g), $\mathrm{Ac}_{2} \mathrm{O}$ (solvent), act. $\mathrm{Zn}^{0}$ (60 equiv.), $0{ }^{\circ} \mathrm{C}, 45 \mathrm{~min}, 83 \%$. (g) AcCl $(3 \mathrm{~mol} / \mathrm{L}$ in $\mathrm{MeOH}), 0 \sim 6{ }^{\circ} \mathrm{C}, 12 \mathrm{~h}(79 \%$ of 82 and $11 \%$ of 81 ). (h) $\mathrm{PPh}_{3}$ (6.6 equiv.), [RhCl(PPh $)_{3}$ ] (5 mol\%), THF, $i-\mathrm{PrOH} ; \mathrm{TMSCHN}_{2}$ (20 equiv.), $48 \mathrm{~h}, 63 \%$. (i) (1) PDC (5 equiv.), DMF, r.t., $18 \mathrm{~h}$; (2) $\mathrm{NaClO}_{2}$ (6 equiv.), $\mathrm{NaH}_{2} \mathrm{PO}_{4}$ (10 equiv.), 2-methyl-2-butene (10 equiv.), THF/t-BuOH, $0{ }^{\circ} \mathrm{C}$ to r.t., $16 \mathrm{~h}, 78 \%$ overall. (j) $\mathrm{HBr}$ (48\% aq.) $\mathrm{Et}_{2} \mathrm{O}$, r.t., $15 \mathrm{~h}, 90 \%$. (k) (1) $\mathrm{HBr}\left(48 \%\right.$ aq.) $\mathrm{Et}_{2} \mathrm{O}$, r.t., $18 \mathrm{~h}$; (2) $\mathrm{CrO}_{3}\left(10\right.$ equiv.), acetone, $0{ }^{\circ} \mathrm{C}$ to r.t., $3 \mathrm{~h}, 70 \%$ overall (acac $=$ acetylacetonate, $\mathrm{BRSM}=$ based on recovered starting material, $\mathrm{DEAD}=$ diethyl azodicarboxylate, $\mathrm{PPA}=$ polyphosphoric acid, $\mathrm{PDC}=$ pyridinium dichromate, $\mathrm{DMF}=\mathrm{N}, \mathrm{N}$-dimethylformamide, $\mathrm{TMS}=$ trimethylsilyl)

图式 14 Baran 小组的 $( \pm)$-steviol 和 $( \pm)$-isosteviol 合成工作

Scheme 14 Baran's synthesis of $( \pm)$-steviol and $( \pm)$-isosteviol 


\subsection{4 其他工作}

还有其他一些漂亮工作 ${ }^{[22]}$, 如 Kende 和 Sanfillipo ${ }^{[23]}$ 对 ( \pm )-phyllocladene 的合成, Mori 和 Matsui 对( \pm )-kaurenoic acid 的合成 ${ }^{[24]}$ 和( \pm )-erythroxydiol 的合 成 ${ }^{[25]}$, Kametani 等 ${ }^{[26]}$ 对 $( \pm)$-hibaol 的合成等, 在此就不 予以一一展示(图 2).

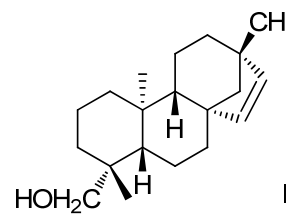

( \pm )-erythroxydiol

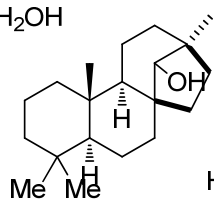

( \pm -hibaol

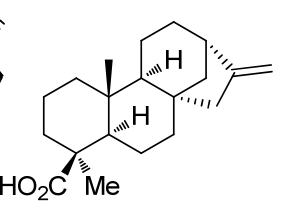

( \pm )-kaurenoic acid
图 2 ( \pm )-erythroxydiol, $( \pm)$-hibaol 和 $( \pm)$-kaurenoic acid 的结 构

Figure 2 Structures of $( \pm)$-erythroxydiol, $( \pm)$-hibaol and $( \pm)$ kaurenoic acid

\section{C-20 位被氧化的对映-贝壳杉烷}

与 $\mathrm{C}-20$ 位没有被氧化的对映一贝壳杉烷相反, C-20 位被氧化的对映-贝壳杉烷的 C-20 位通常是甲醛基、接 氧次甲基或羰基，这类分子分布同样分布广泛.

\subsection{Corey 组对(土)-neotripterifordin 的合成}

Neotripterifordin 提取自中国药用植物昆明山海 棠 ${ }^{[27]}$, 具有很好的抑制 HIV 复制的生物活性 $\left(\mathrm{EC}_{50}=25\right.$ $\mathrm{nmol} / \mathrm{L})^{[28]}$. (土)-neotripterifordin 的结构最开始被定为 92, 如果这一结构是正确的, 那么, 综合五元环的拓扑 结构、立体化学等多方面因素考虑, 对这一分子的合成 将是一个非常有挑战性的工作. Corey 等 ${ }^{[29]}$ 完成了对其
对映选择性的全合成工作，并将其结构由 92 修正为 91 .

在 Corey 的合成工作中, 绝对立体构型由对映选择 性的环氧化反应和环氧乙烷引发的阳离子一烯烃多环化 反应的联合作用实现. 经过 Birch 还原反应、光催化的 $[2+2]$ 环加成反应、臭氧分解反应以及 Seyferth-Gilbert 同系化反应在 C-8 位立体选择性的引入炔丙基得到 89. 89 经过自由基偶联反应得到四环体系 90.90 可以经过 不同的转化途径得到 91 和 92, 将它们的氢谱、碳谱、 质谱、旋光及薄层色谱信息与 $( \pm)$-neotripterifordin 进行 比对发现, 91 与 $( \pm)$-neotripterifordin 在各方面完全相同, 实现了对(士)-neotripterifordin 结构的修正(Scheme 15).

\section{C-6,7 位断裂的贝壳杉烷}

这一类分子可以看作是 7,20-环氧一贝壳杉烷发生 $\mathrm{C}(6)-\mathrm{C}(7)$ 键氧化切断的产物. 根据结构上的性质, 这 类分子还可以被分为延命草素型(1,7-内酯型)和螺内酯 型(7,20-内酯型). 从生源合成观点看, 如果在 C-1 位没 有取代, 则氧化切断会得到 7,20-内酯型; 如果 C-1 位有 一个处于直立键的羟基时，将得到 1,7-内酯型.

\subsection{Eiichi Fujita 组对( \pm )-enmein 的合成}

Enmein 于 20 世纪 60 年代被分离自 I. trichocarpa ${ }^{[30]}$, 通过 X-ray 晶体学分析 ${ }^{[31]}$ 阐述了其结构为 6,7-位断裂的 对映贝壳杉烷. Fujita 课题组 ${ }^{[32]}$ 于 1974 年完成了对 (土)-enmein 的全合成工作. 他们以化合物 93 为起始原 料, 首先转化为中间体 94, 经过消除反应进一步转化为 $\mathrm{C}(6)-\mathrm{C}(7)$ 为双键的中间体 95. 化合物 95 经过 $\mathrm{C}(6)-$ $\mathrm{C}(7)$ 键的氧化切断并经过一系列转化得到 $\mathrm{B}$ 环切断的对 映-贝壳杉烷衍生物 96, 酮-双内酯中间体 96 经过 C-3

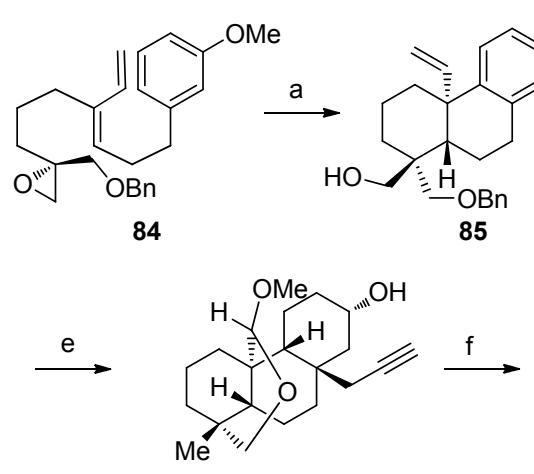

89
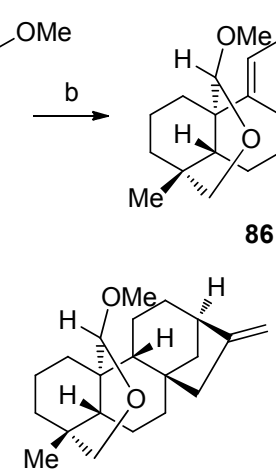

90

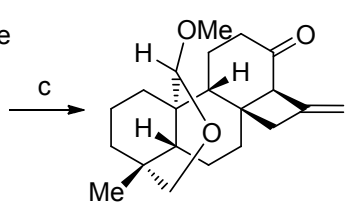

87

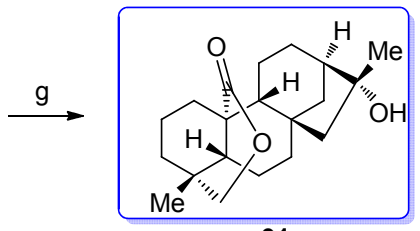

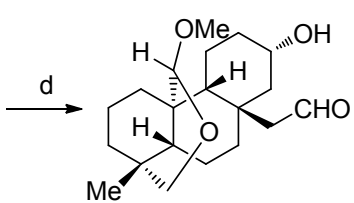

88

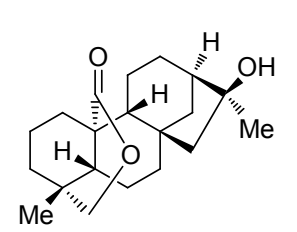

92

Reagents and conditions: (a) $\mathrm{TiCl}_{4}$ (1.2 equiv.), $\mathrm{CH}_{2} \mathrm{Cl}_{2},-94{ }^{\circ} \mathrm{C}, 10$ min, $86 \%$. (b) (1) Dess-Martin periodinane, $\mathrm{CH}_{2} \mathrm{Cl}_{2}$; (2) $\mathrm{H}_{2} \mathrm{NNH}_{2}, \mathrm{~K}_{2} \mathrm{CO}_{3}$, bis(ethylene glycol), $210{ }^{\circ} \mathrm{C}$; (3) $\mathrm{OsO}_{4}$ (1.1 equiv.), $t-\mathrm{BuOH}-\mathrm{H}_{2} \mathrm{O}$; (4) $\mathrm{NalO}_{4}$, dioxane- $\mathrm{H}_{2} \mathrm{O}$; (5) $\mathrm{H}_{2}$ (balloon), 10\% $\mathrm{Pd}-\mathrm{C}$ (cat.), AcOH (cat.), $\mathrm{MeOH}, 76 \%$ overall. (c) (1) $\mathrm{Li}, \mathrm{NH}_{3}(I)$, THF-t-BuOH; (2) $\mathrm{HCl}, \mathrm{MeOH}$; (3) allene, $\mathrm{h} v(300 \sim 360 \mathrm{~nm})$, hexane, $-30{ }^{\circ} \mathrm{C}, 30 \mathrm{~min}, 54 \%$ overall. (d) (1) $\mathrm{O}_{3}, \mathrm{NaHCO}_{3}, \mathrm{MeOH},-78{ }^{\circ} \mathrm{C}$; then $\mathrm{Me}_{2} \mathrm{~S}$; (2) DIBAL-H (2.0 equiv.), toluene, $-78{ }^{\circ} \mathrm{C}, 66 \%$. (e) $\mathrm{CH}{ }_{3} \mathrm{COC}\left(\mathrm{N}_{2}\right) \mathrm{PO}(\mathrm{OMe})_{2}, \mathrm{~K}_{2} \mathrm{CO}, \mathrm{MeOH}_{3}$ $94 \%$. (f) (1) $\mathrm{NaH}$, imidazole (cat.), THF, reflux, then $\mathrm{CS}_{2}$, then Mel; (2) $n-\mathrm{Bu}_{3} \mathrm{SnH}$, azoisobutyronitrile, toluene, $110{ }^{\circ} \mathrm{C}$, 10 min, $87 \%$ overall. (g) (1) $m$-CPBA, $\mathrm{NaHCO}_{3}, \mathrm{CH}_{2} \mathrm{Cl}_{2}$; (2) $\mathrm{LiAlH}_{4}, \mathrm{Et}_{2} \mathrm{O}$; (3) $\mathrm{HCl}, \mathrm{THF}-\mathrm{H}_{2} \mathrm{O}$; (4) Dess-Martin periodinane, 64\% overall

图式 15 Corey 小组的 $( \pm)$-neotripterifordin 合成工作

Scheme 15 Corey's synthesis of $( \pm)$-neotripterifordin 
位和 C-6 位的立体选择性羟基引入以及对 D 环的修饰, 最终合成 $( \pm)$-enmein. 在这一路线中, C-6 位羟基消除 可以发生在 C-5,6 位和 C-6,7 位之间(1：2), C-6,7 位之间 的双键的臭氧解反应产率只有 $13 \%$ (Scheme 16).

\subsection{Mander 组对( \pm )-15-desoxyeffusin 的合成}

Effusin 是螺内酯型 6,7-位断裂的对映贝壳杉烷. Mander 等 ${ }^{[33]}$ 以已知的合成中间体 98 出发, 通过合成 102 再发生 $\mathrm{C}(6)-\mathrm{C}(7)$ 键的切断实现对 $( \pm)-15$-desoxyeffusin 的合成. 在这一策略中, 作者先立体选择性的构 建 $\mathrm{B} / \mathrm{C} / \mathrm{D}$ 环体系, 通过 C-10 位的手性经分子内 Micheal 加成反应和分子内卤原子取代反应分别控制 C-5 位和 C-4 位的手性(Scheme 17).
3.3 Reisman 组对(-)-maoecrystal $Z$ 和(-)-trichorabdal $A$ 的合成

Maoecrystal Z 分离自中国传统中药毛萼香茶菜 ${ }^{[34]}$, 是 C-6,7 位断裂的对映-贝壳杉烷的重排产物，在其紧凑 的四环结构中结构中包含了六个立体中心, 其中两个为 四级碳中心. 2011 年, Reisman 小组 ${ }^{[35]}$ 完成了对 (一)-maoecrystal $\mathrm{Z}$ 的首次全合成. 他们首先从 $(-)-\gamma$ cyclogeraniol 出发, 经过对一级醇的保护和 $m$-CPBA 的 环氧化作用得到环氧化物 $\mathbf{1 0 4}$, 再通过 $\mathrm{Ti}^{\mathrm{III}}$ 介导的还原 偶联反应完成对中间体螺内酯化合物 105 的合成. 在这 一过程中，他们首先使用丙烯酸甲酯，但是可能是因为 Lewis 酸介导的环氧重排反应产生大量丙烯醇副产物
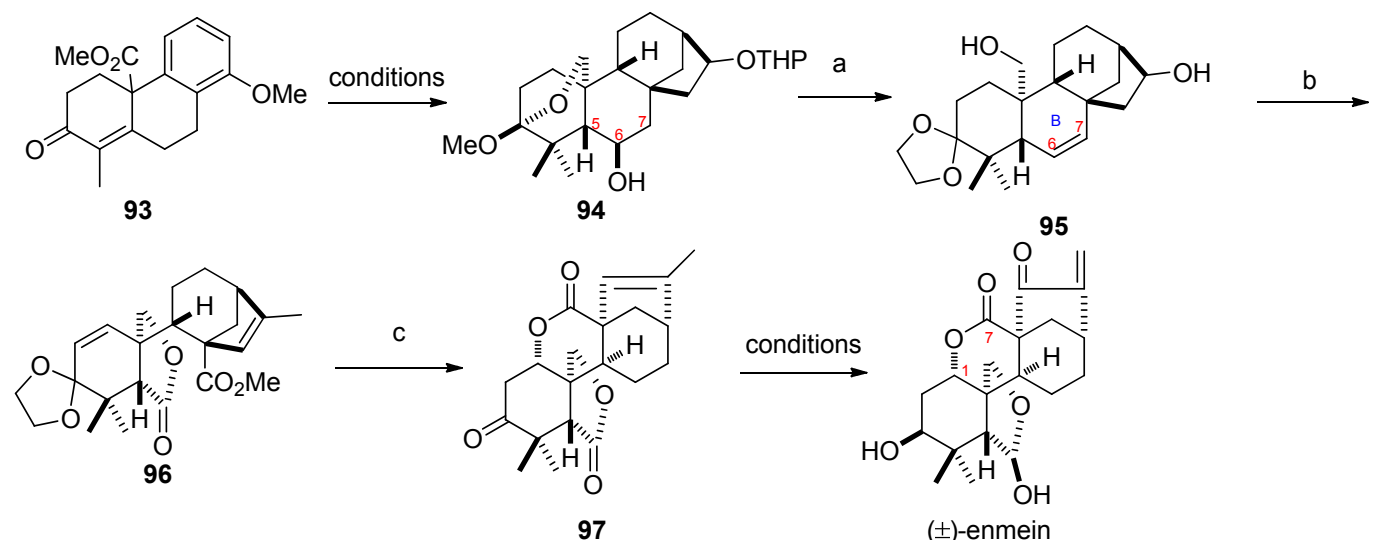

Reagents and conditions: (a) (1) $p$ - $\mathrm{TsOH}, \mathrm{MeOH}$; (2) dihydropyran, $\mathrm{CHCl}_{3}$; (3) $\mathrm{SOCl}_{2}$, pyridine; (4) $\mathrm{HOCH}_{2} \mathrm{CH}_{2} \mathrm{OH}, p$ - $\mathrm{TsOH}$, toluene, $25 \%$ overall. (b) (1) $\mathrm{O}_{3}, \mathrm{MeOH}$; (2) Jones reagent, acetone, $13 \%$ overall; (3) $t$ - $\mathrm{BuOK}$, Methyltriphenylphosphonium lodide, $\mathrm{Et}_{2} \mathrm{O}, 80 \%$; (4) $5 \% \mathrm{HCl}$, acetone, 47\%; (5) $\mathrm{Br}_{2}, \mathrm{AcOH}, 85 \%$; (6) 2,4,6-collidine, heat (in sealed tube), $68 \%$; (7) DMSO, $170^{\circ} \mathrm{C}, 15 \%$; (8) $\mathrm{HOCH}_{2} \mathrm{CH} \mathrm{H}_{2} \mathrm{OH}, p$ - $\mathrm{TsOH}$, toluene, $88 \%$. (c) (1) $10 \% \mathrm{KOH}$ (in $\mathrm{MeOH}$ ), reflux, quantitive; (2) $\mathrm{BF}_{3} \cdot \mathrm{Et}_{2} \mathrm{O}, \mathrm{CHCl}_{3}, 72 \%$; (3) $5 \% \mathrm{H}_{2} \mathrm{SO}_{4}$, acetone, $22 \%$

图式 16 Eiichi Fujita 小组的 $( \pm)$-enmein 合成工作

Scheme 16 Eiichi Fujita's synthesis of $( \pm)$-enmein

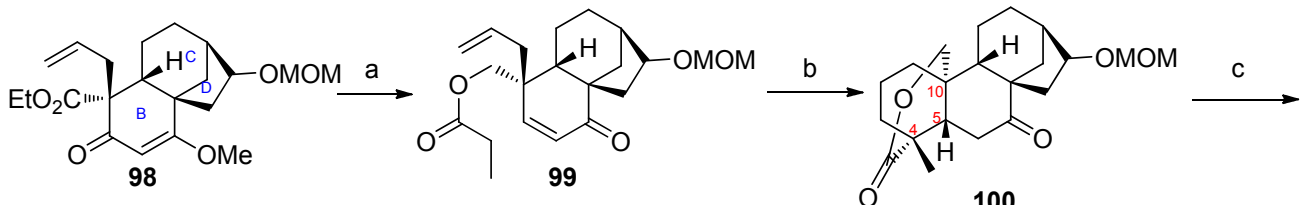

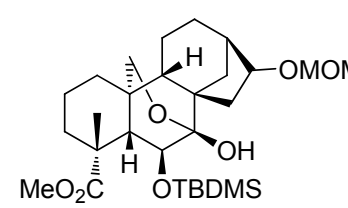

101

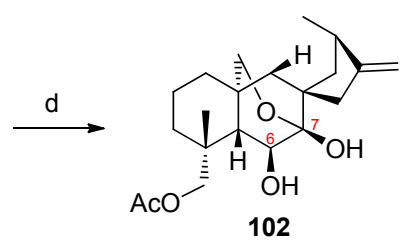

102

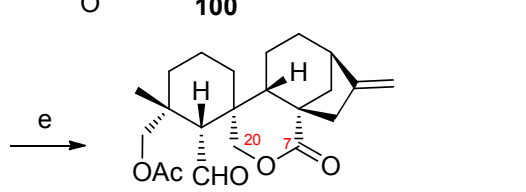

$( \pm)$-15-desoxyeffusin

Reagents and conditions: (a) (1) $\mathrm{NaAl}\left(\mathrm{OCH}_{2} \mathrm{CH}_{2} \mathrm{OMe}\right)_{2} \mathrm{H}_{2}$, toluene, $25^{\circ} \mathrm{C}$; (2) $p$ - TsOH, $\mathrm{PhH}, 25^{\circ} \mathrm{C}$; (3) (EtCO) ${ }_{2} \mathrm{O}, \mathrm{DMAP}$, pyridine, $25^{\circ} \mathrm{C}, 54 \%$ overall. (b) (1) $\mathrm{KH}, \mathrm{DMF},-30{ }^{\circ} \mathrm{C}$; (2) $\mathrm{NaB}(\mathrm{CN}) \mathrm{H}_{3}, \mathrm{MeOH}, 30{ }^{\circ} \mathrm{C}$; (3) TBDMSOTf, 2,6-lutidine, 1,2-Dichloroethane, $25{ }^{\circ} \mathrm{C}$; (4) $\mathrm{Me}_{2} \mathrm{CHCH}(\mathrm{Me})_{2} \mathrm{BH}_{2}$, diglyme, $\mathrm{Me}_{3} \mathrm{NO}, 100^{\circ} \mathrm{C}$; (5) $\mathrm{Ph}_{3} \mathrm{P}, \mathrm{CBr}_{4}$, pyridine; (6) LDA, THF, $-20^{\circ} \mathrm{C}$; (7) TBAF, THF, $25^{\circ} \mathrm{C} ;(8)\left(\mathrm{PyH}_{2} \mathrm{Cr}_{2} \mathrm{O}_{7}, \mathrm{CH}_{2} \mathrm{Cl}_{2}\right.$, $25{ }^{\circ} \mathrm{C}, 27 \%$ overall. (c) (1) TBDMSOTf, TEA, $25{ }^{\circ} \mathrm{C}$; (2) $\mathrm{m}$-CPBA, $\mathrm{CH}_{2} \mathrm{Cl}_{2}, 25^{\circ} \mathrm{C}$; (3) $\mathrm{KOH}, \mathrm{MeOH}, 25{ }^{\circ} \mathrm{C}$; (4) $\mathrm{CH}_{2} \mathrm{~N}_{2}$, Et $\mathrm{Et}_{2} \mathrm{O}, 87 \%$ overall. (d) (1) $\mathrm{LiAlH}_{4}$, THF, $25^{\circ} \mathrm{C}$; (2) $\mathrm{Ac}_{2} \mathrm{O}$, pyridine; (3) $\mathrm{Me}_{2} \mathrm{BBr}$, TEA, $-78{ }^{\circ} \mathrm{C}$; (4) $(\mathrm{PyH})_{2} \mathrm{Cr}_{2} \mathrm{O}_{7}, \mathrm{CH}_{2} \mathrm{Cl}_{2}, 25^{\circ} \mathrm{C}$; (5) $i$-AmOK, Methyltriphenylphosphonium bromide, toluene, $25^{\circ} \mathrm{C}, 53 \%$. (e) (1) TBAF, THF, $25^{\circ} \mathrm{C}$; (2) $\mathrm{H}_{5} \mathrm{IO}_{6}, \mathrm{Et}_{2} \mathrm{O}, 85 \%$

图式 17 Mander 小组的 $( \pm)$-15-desoxyeffusin 合成工作

Scheme 17 Mander's synthesis of $( \pm)$-15-desoxyeffusin 
106. 通过对条件的篮选, 他们决定使用更为亲电的 2,2,2-三氟乙基丙烯酸酯, 从而以较高产率得到化合物 105. 化合物 105 经过与碘代物的烷基化反应形成化合 物 107 , 再经过硒化/氧化反应以及对端位双键的切断反 应转化为醛 109. 在 $\mathrm{SmI}_{2}$ 作用下实现环化构建四环二醇 中间体 110. 对二醇 110 的乙酰基保护和端位烯烃的臭 氧化切断后与 Eschenmoser 盐反应得到乙酰 maoecrystal $Z$, 再通过选择性的脱除乙酰基得到终产物 (一)-maoecrystal Z. 在这一合成中, $\mathrm{Ti}^{\mathrm{III}}$ 介导的环氧的还 原偶联反应和 $\mathrm{SmI}_{2}$ 介导的还原串联环化反应是关键步 骤(Scheme 18).

2013 年, Reisman 等 ${ }^{[36]}$ 实现了 (一)-trichorabdal A 的 首次全合成. 在以往的对 C-6,7 位断裂的对映一贝壳杉烷
的合成策略中，都是先合成 $\mathrm{A} / \mathrm{B} / \mathrm{C} / \mathrm{D}$ 环系完整的骨架结 构后，再对 $\mathrm{C}(6)-\mathrm{C}(7)$ 键进行切断得到对应的 C-6,7 位 断裂的对映贝壳杉烷的骨架结构，Reisman 采用了不同 的策略.

在对(一)-trichorabdal A 的合成路线中, Reisman 使 用了之前在合成(一)-maoecrystal Z 时使用的中间体 108 . 选择性的切断双硅基保护的 108 中比较容易接近的硅醚 键并发生 Dess-Martin 氧化合成醛 112, 经过 $\mathrm{SmI}_{2}$ 介导 的还原环化反应得到单一的非对映异构体 113, 保护裸 露的二级醇后, 用 KHMDS 去质子化并用 $\mathrm{TBSCl}$ 捕获生 成 $\mathrm{Pd}^{\mathrm{II}}$ 介导的氧化环化反应前体 115 . 经过对多种 $\mathrm{Pd}(\mathrm{II})$ 试剂、添加剂及溶剂的篮选，以 $56 \%$ 的产率实现这一转 化得到重要中间体 116 (Scheme 19).
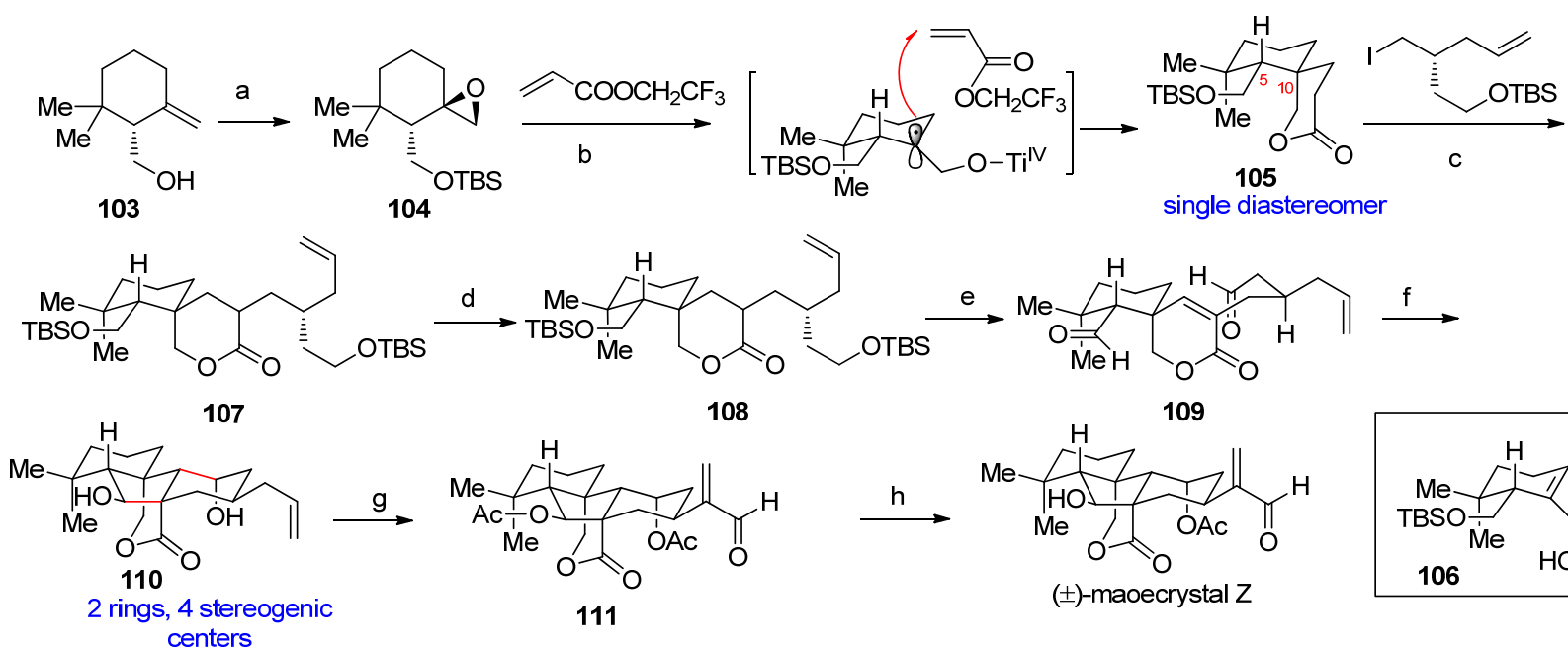

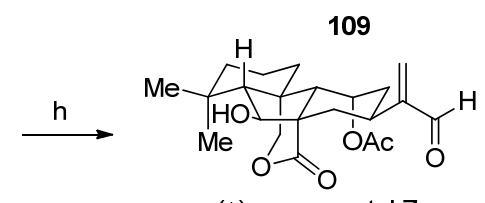

(土)-maoecrystal Z

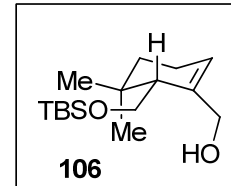

106

Reagents and conditions: (a) (1) TBSCl, imid., $\mathrm{CH}_{2} \mathrm{Cl}_{2}$; (2) $m$-CPBA, $\mathrm{NaHCO}_{3}, \mathrm{CH}_{2} \mathrm{Cl}_{2}, 91 \%$ in two steps. (b) $\mathrm{Cp}_{2} \mathrm{TiCl}_{2}\left(1.6 \mathrm{equiv}\right.$ ), $\mathrm{Zn}^{0}$ (1.5 equiv.), 2,4,6-collidine• $\mathrm{HCl}$ (3.0 equiv.), THF, 74\%. (c) LiHMDS, THF/HMPA ( $V: V=4: 1$ ), $74 \%$. (d) $\mathrm{KHMDS}, \mathrm{PhSeBr}$, then $\mathrm{H}_{2} \mathrm{O}_{2}, 81 \%$. (e) (1) $\mathrm{H}_{2} \mathrm{SiF}_{6}, \mathrm{MeCN}$; (2) DMP, $\mathrm{CH}_{2} \mathrm{Cl}_{2}, 86 \%$ in two steps. (f) $\mathrm{Sml}$, $\mathrm{LiBr}$, $t$-BuOH, THF, 54\%. (g) (1) $\mathrm{Ac}_{2} \mathrm{O}, \mathrm{TMSOTf}, \mathrm{CH}_{2} \mathrm{Cl}_{2} ;(2) \mathrm{O}_{3}, \mathrm{CH}_{2} \mathrm{Cl}_{2}, \mathrm{then} \mathrm{Et}_{3} \mathrm{~N}$; (3) $\mathrm{Et}_{3} \mathrm{~N}, \mathrm{CH}_{2} \mathrm{Cl}_{2}$, Eschenmoser's salt, $59 \%$ overall. (h) $1 \mathrm{~mol} / \mathrm{L} \mathrm{NaOH}\left[\mathrm{V}(\mathrm{MeOH}) / \mathrm{V}\left(\mathrm{H}_{2} \mathrm{O}\right)=1 / 1\right], 38 \%$

图式 18 Reisman 小组的(-)-maoecrystal Z 合成工作

Scheme 18 Reisman's synthesis of (-)-maoecrystal Z

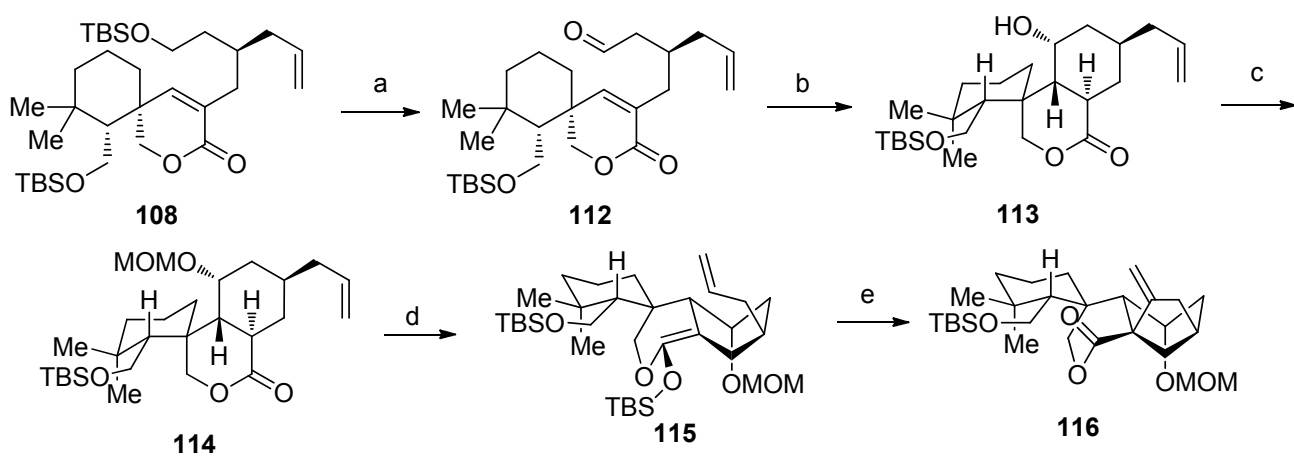

Reagents and conditions: (a) (1) KHMDS, $-78{ }^{\circ} \mathrm{C}$, PhSeBr, then $\mathrm{H}_{2} \mathrm{O}_{2}$; (2) DMP, $\mathrm{CH}_{2} \mathrm{Cl}_{2}, 77 \%$ in two steps. (b) $\mathrm{Sml} 2, \mathrm{LiBr}, t-\mathrm{BuOH}, \mathrm{THF}, 57 \%$. (c) $\mathrm{MOMCl}, n$-Bu, NI, DIPEA, DMF, 91\%. (d) KHMDS, TBSCI, DMPU, THF, $85 \%$. (e) $\mathrm{Pd}(\mathrm{AcO})_{2}, \mathrm{AcOH}$, DMSO, air, $56 \%$

图式 19 Reisman 组对中间体 116 的合成

Scheme 19 Reisman's synthesis of the intermediate 116 
116 的五元环外双键臭氧化切断后, 经过羰基 $\alpha$-位 亚甲基化反应、去保护反应、一级醇选择性的氧化反应 得到目标天然产物(一)-trichorabdal A (Scheme 20).

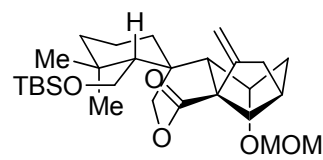

116

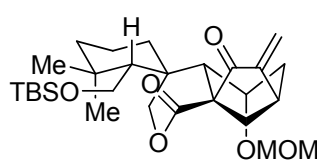

118

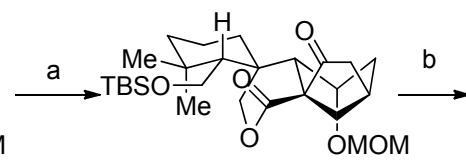

117

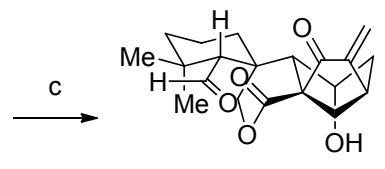

(-)-trichorabdal A
Reagents and conditions: (a) $\mathrm{O}_{3}, \mathrm{CH}_{2} \mathrm{Cl}_{2}$, then $\mathrm{Ph}_{3} \mathrm{P}, 69 \%$. (b) $\mathrm{Me}_{2} \mathrm{NCH}_{2} \mathrm{NMe}_{2}, \mathrm{Ac}_{2} \mathrm{O}$, DMF, 82\%. (c) (1) $6 \mathrm{~mol} / \mathrm{L} \mathrm{HCl}$ (aq.), dioxane; (2) TEMPO, $\mathrm{Phl}(\mathrm{OAc})_{2}, \mathrm{CH}_{2} \mathrm{Cl}_{2}, 73 \%$ in two steps

图式 20 Reisman 对(一)-trichorabdal A 的合成

Scheme 20 Reisman's synthesis of (-)-trichorabdal A

同时, Reisman 也完成了对(一)-longikaurin E 的全合 成(这一分子属于 C-20 位被氧化的对映-贝壳杉烷). 如 果 116 先经过脱保护反应、选择性的一级醇氧化反应、 二级醇的乙酰基保护反应生成 119 后, 经过 $\mathrm{SmI}_{2}$ 介导的 频哪醇类型偶联反应可以获得单一非对映选择性的内 半缩醛 120, 最后经过臭氧切断反应及羰基 $\alpha$-位亚甲基 化反应得到目标天然产物(一)-longikaurin E (Scheme 21).
116

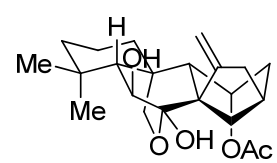

120

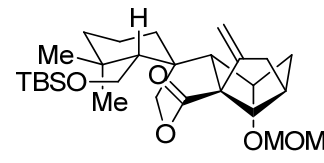

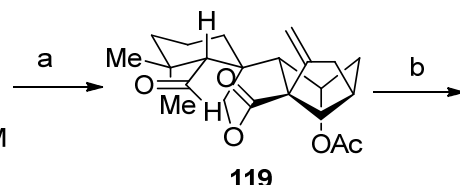

119

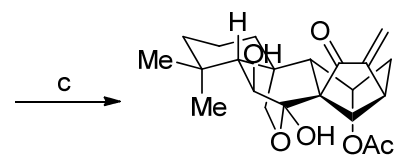

(-)-longikaurin $\mathrm{E}$
Reagents and conditions: (a) (1) $6 \mathrm{~mol} / \mathrm{L} \mathrm{HCl}$ (aq.), dioxane; (2) TEMPO, $\mathrm{Phl}(\mathrm{OAc})_{2}$; (3) Ac $\mathrm{Ac}_{2} \mathrm{O}$, DMAP, $52 \%$ overall. (b) $\mathrm{Sml}_{2}$, THF, $55 \%$. (c) $\mathrm{O}_{3}, \mathrm{CH}_{2} \mathrm{Cl}_{2}$, then $\mathrm{Ph}_{3} \mathrm{P}$; (2) $\mathrm{Me}_{2} \mathrm{NCH}_{2} \mathrm{NMe}_{2}, \mathrm{Ac}_{2} \mathrm{O}, \mathrm{DMF}$, $44 \%$ in two steps

图式 21 Reisman 对(一)-longikaurin E 的合成

Scheme 21 Reisman's synthesis of (-)-longikaurin E

该合成的关键步骤是 $\mathrm{Pd}^{\mathrm{II}}$ 介导的氧化环化和 $\mathrm{SmI}_{2}$ 介导的频哪醇类型偶联反应.

\section{C-8,9 位断裂的对映-贝壳杉烷}

C-8,9 位断裂的对映-贝壳杉烷从生源上看, 是由
C-9 位具有羟基的对映-贝壳杉烷经过逆 Aldol 反应使得 $\mathrm{C}(7)-\mathrm{C}(8)$ 键的断裂，同时失去一分子水在 $\mathrm{C}-8,14$ 或 C-7,8 之间形成双键而得到的.

\subsection{Paquette 对(-)-O-methylshikoccin 的合成}

Paquette 发现, 二环[7.2.1]-dodecene 在结构上与 $O$-methylshikoccin 的 B/C 环非常相近, 并且 122 可以由 121 经过[3.3] sigmatropic 重排反应得到 ${ }^{[37]}$, 他们将这一 转化应用于 $O$-Methylshikoccin 的合成中 ${ }^{[38]}$ (Eq. 1).

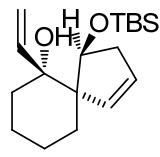

121

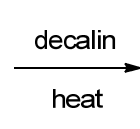

heat

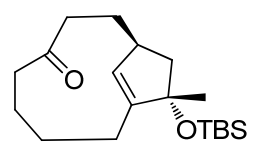

122
于是他们首先合成了具有化合物 121 骨架结构的 127. 在合成 127 的过程中, 首先实现了 $\mathrm{A} / \mathrm{B}$ 环相对立体 构型的控制. 从具有手性的 123 出发, 经过 Woodward 甲基化反应、立体选择性的还原反应、烯丙位氧化反应 等一系列反应在 $\mathrm{A}$ 环上引入甲基和保护的羟基. 接下来 是对螺环的构建. 通过对二酮的烷基化反应得到的化合 物 125 发生环化反应及必要的官能团转化得到 127 , 进 一步在 $230 \sim 240{ }^{\circ} \mathrm{C}$ 条件下发生 oxy-Cope 重排并经过 Dess-Martin 氧化反应和羰基 $\alpha$ 位亚甲基化反应得到 (-)-O-methylshikoccin (Scheme 22).

\section{5 其他类型的对映贝壳杉烷}

\section{1 杨震对( \pm )-maoecrystal $V$ 的合成}

Maoecrystal V 于 2004 年由孙汉董院士等 ${ }^{[39]}$ 分离自 中国传统中药 Isodon eriocalyx, 这一 C(19)二萜具有有 对 Hela 细胞选择性抑制活性 $\left(\mathrm{IC}_{50}=60 \mathrm{nmol} / \mathrm{L}\right)$. Maoecrystal $\mathrm{V}$ 具有一个高度拥挤的五环骨架, 并且有六个 立体中心, 其中有三个临近的四级碳立体中心. 它的这 一结构是通过 X-ray 单晶衍射确定的. 由于其具有迷人 的结构和卓越的生物活性, Maoecrystal V 受到合成化学 家的广泛关注.

杨震课题组 ${ }^{[40]}$ 于 2010 年完成了对 $( \pm)$-maoecrystal $\mathrm{V}$ 的首次全合成. 他的课题组 ${ }^{[41]}$ 之前已经报道了通过氧 化去芳构化反应和分子内 Diels-Alder 反应构建 maoecrystal V 的骨架结构, 通过这一反应可以一步引入两个 相邻的四级碳立体中心同时构建一个三环刚性体系, 这 一策略应用于 134 到 136 的转化这一过程中会产生 $135 \mathrm{a}$ 和 $135 \mathrm{~b}$ 两个副产物. 134 可以通过 HornerWadsworth-Emmons 反应由 133 转化而来. 133 可以通过 132 发生金属催化的 $\mathrm{O}-\mathrm{H}$ 键插入反应获得. 在对 $\beta$-酮 酯 129 还原时发现, 得到的顺势二醇 $130 \mathrm{a}$ 与反式二醇 $130 \mathrm{~b}$ 的比值为 $1: 6$, 量少的顺势二醇恰恰是想要的. 


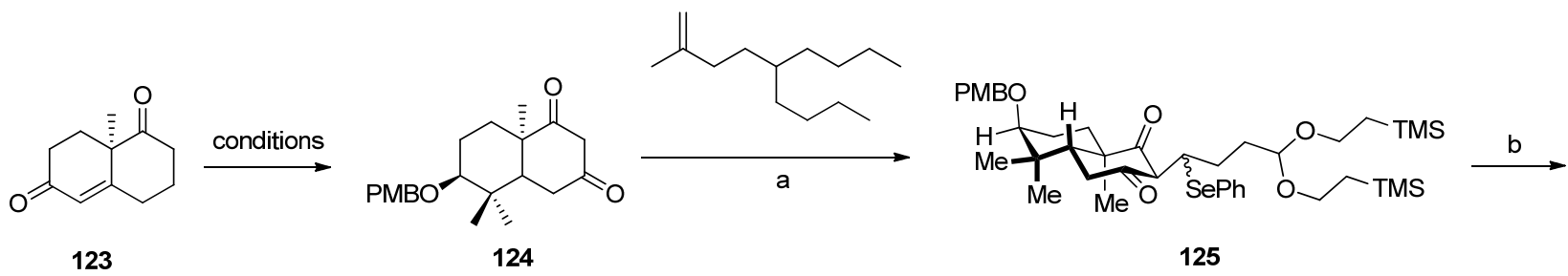

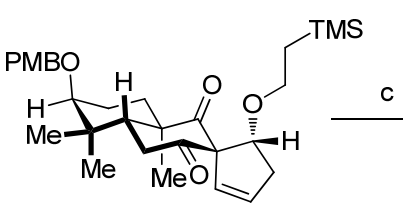

126

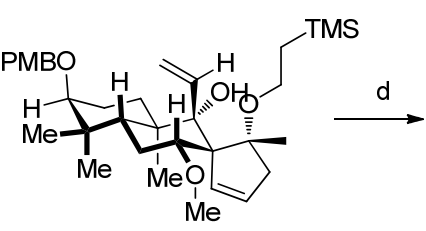

127

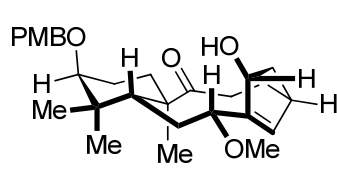

128

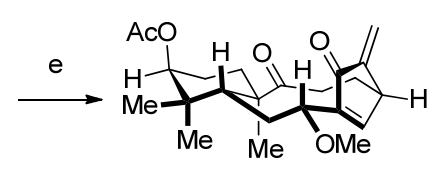

(-)-O-methylshikoccin

Reagents and conditions: (a) PhSeH, $\mathrm{SiO}_{2}, 4 \AA \mathrm{MS}, \mathrm{CH}_{2} \mathrm{Cl}_{2}$. (b) (1) $\mathrm{LiBF}_{4}, \mathrm{CH}_{3} \mathrm{CN}, \mathrm{H}_{2} \mathrm{O}$; (2) $\mathrm{H}_{2} \mathrm{O}_{2}$, pyridine, $\mathrm{EtOCH}=\mathrm{CH}_{2}, \mathrm{CH}_{2} \mathrm{Cl}_{2}, 51 \%$. (c) (1) (i-Bu) ${ }_{2} \mathrm{AlH}$, THF; (2) Mel, $\mathrm{Ag}_{2} \mathrm{O}, \mathrm{CaSO}_{4}$; (3) $\mathrm{CH}_{2}=\mathrm{CHMgBr}$, THF, $13 \%$ overall. (d) (1) $230 \sim 240{ }^{\circ} \mathrm{C}$, DMF; (2) CsF, DMF, $210{ }^{\circ} \mathrm{C}, 65 \%$. (e) (1) DMP, pyridine, $\mathrm{CH}_{2} \mathrm{Cl}_{2}$; (2) KHMDS, TMSCl, THF; (3) $\mathrm{Me}_{2} \mathrm{~N}^{+}=\mathrm{CH}_{2} \mathrm{I}^{-}$, DMF, $\mathrm{NaOH}$; (4) Mel, ether; (5) $\mathrm{K}_{2} \mathrm{CO}_{3}, \mathrm{H}_{2} \mathrm{O}, \mathrm{CH}_{2} \mathrm{Cl}_{2}$; (6) $\mathrm{DDQ}, \mathrm{CH}_{2} \mathrm{Cl}_{2}$, $\mathrm{H}_{2} \mathrm{O}$; (7) $\mathrm{Ac}_{2} \mathrm{O}$, pyridine, DMAP, $\mathrm{CH}_{2} \mathrm{Cl}_{2}, 55 \%$ overall

图式 22 Paquette 对(一)-O-methylshikoccin 的合成

Scheme 22 Paquette's synthesis of $(-)$-O-methylshikoccin

于是他们选择了分步的方法, 即先将 129 的羰基还原为 羟基在对酯基进行还原, 他们发现使用 $\left(n-\mathrm{Bu}_{4}\right) \mathrm{NBH}_{4}$ 在 甲醇中进行还原可以得到单一构型的 131a，对这一非 对映立体选择性的解释为铵盐 $\left[\left(n-\mathrm{Bu}_{4}\right) \mathrm{NBH}_{4}\right]$ 与 129 中 苯环之间的阳离子- $\pi$ 相互作用(Scheme 23).

在得到 136 后, 通过在 $\mathrm{C}-1$ 位引入溴原子并在
$\mathrm{Bu}_{3} \mathrm{SnH}$ 作用下产生烯丙基自由基，经 TEMPO 捕获并经 过区域选择性地还原切断四甲基哌啶和乙酰氧基获得 单一立体构型的 137. 137 经过 Lindlar 催化的区域选择 性的加氢反应和 Dess-Martin 氧化氧化得到 138, 最终在 $\mathrm{DBU}$ 作用下实现 $\mathrm{C}-16$ 位甲基手性的翻转得到 (士)-maoecrystal V. (Scheme 24).

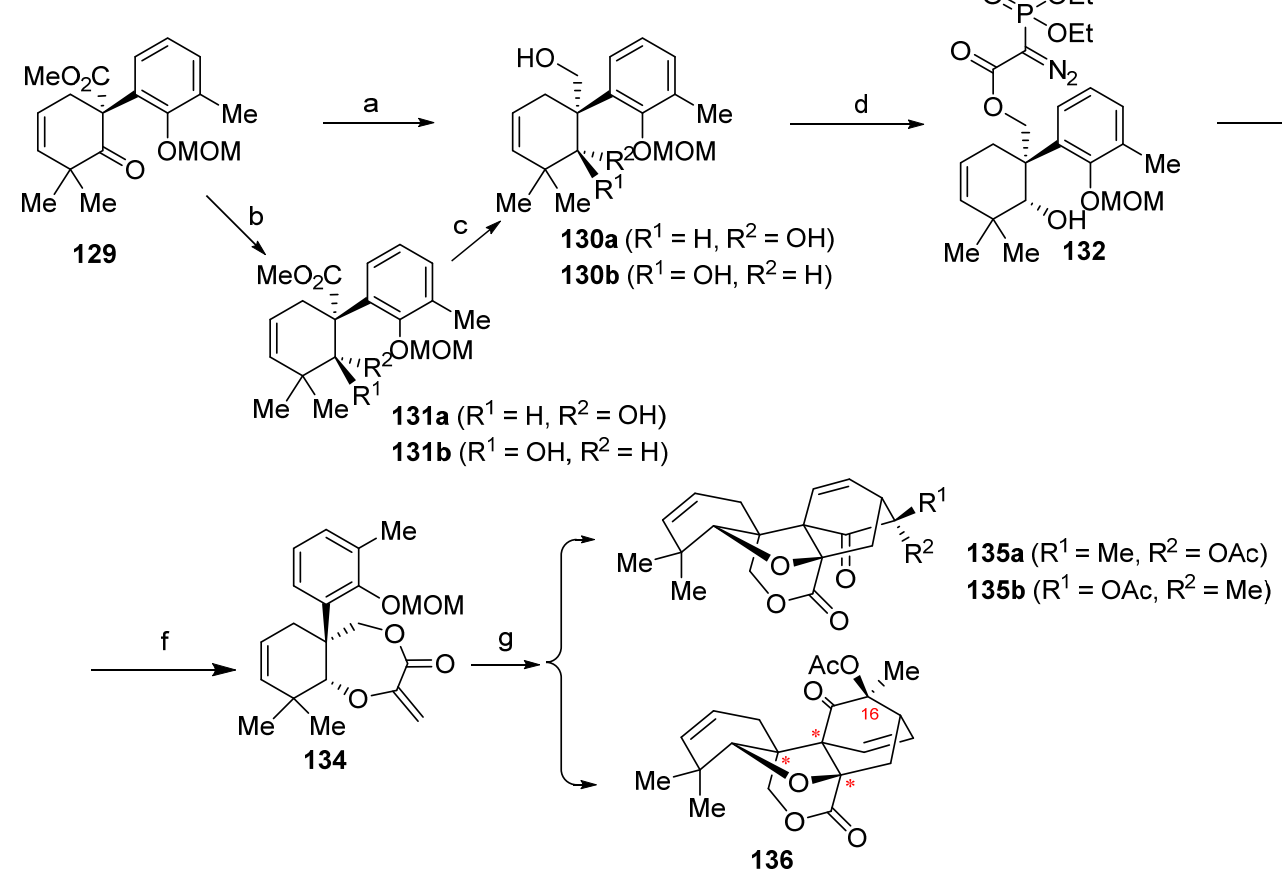

Reagents and conditions: (a) $\mathrm{LiAlH}_{4}$, THF, 130a (12\%) and 130b (72\%). (b) $\left(\mathrm{Bu}_{4} \mathrm{~N}\right) \mathrm{BH}_{4}, \mathrm{MeOH}, 65 \%$. (c) $\mathrm{LiAlH}_{4}, \mathrm{THF}, 88 \%$. (d) (1) 2-(diethoxyphosphoryl)acetic acid, EDCl, DMAP, $\mathrm{CH}_{2} \mathrm{Cl}_{2}, 82 \%$; (2) $\mathrm{TsN}_{3}, \mathrm{DBU}, 81 \%$. (e) $\mathrm{Rh}_{2}(\mathrm{OAc})_{4}, \mathrm{PhH}, 60 \%$. (f) (1) $t$ - $\mathrm{BuOK},(\mathrm{HCHO})$, THF, 95\%; (2) TFA, $\mathrm{CH}_{2} \mathrm{Cl}_{2}, 90 \%$. (g) $\mathrm{Pb}(\mathrm{OAc})_{4}, \mathrm{AcOH}, 0^{\circ} \mathrm{C}$, then toluene, $145{ }^{\circ} \mathrm{C}, 135 \mathrm{a}(28 \%), 135 \mathrm{~b}(12 \%), 136(36 \%)$

图式 23 杨震对中间体 $\mathbf{1 3 6}$ 的合成

Scheme 23 Yang's synthesis of intermediate 136 


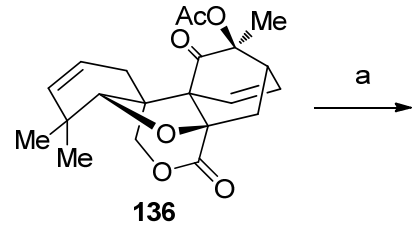

136

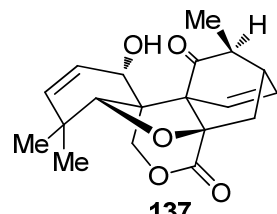

137

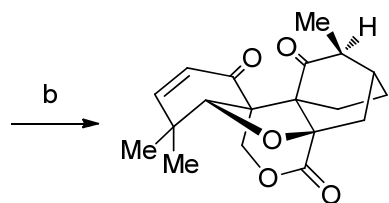

138

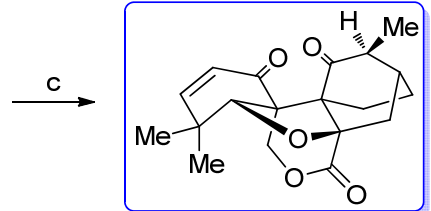

( \pm -maoecrystal V

Reagents and conditions: (a) (1) NBS, $\left(\mathrm{PhCO}_{2}\right)_{2}, \mathrm{CCl}_{4}$, reflux; (2) $\mathrm{Bu}_{2} \mathrm{SnH}$, TEMPO, PhH, reflux; (3) $\mathrm{Zn}, \mathrm{AcOH}, \mathrm{THF}, \mathrm{H}_{2} \mathrm{O}, 70{ }^{\circ} \mathrm{C}$; $(4) \mathrm{Sml}_{2}$, THF, $\mathrm{MeOH}$, r.t., $50 \%$ overall. (b) (1) Lindlar cat. $\mathrm{MeOH}$, THF, r.t.; (2) DMP, $\mathrm{CH}_{2} \mathrm{Cl}_{2}$, r.t., $81 \%$ in two steps. (c) DBU, toluene, $100{ }^{\circ} \mathrm{C}, 48 \%$

图式 24 杨震对( $( \pm)$-maoecrystal V 的合成

Scheme 24 Zhen Yang's synthesis of $( \pm)$-maoecrystal V 的合成

\subsection{Danishefsky 组对 $( \pm)$-maoecrystal $V$ 的合成}

2012 年, Danishefsky 课题组 ${ }^{[42]}$ 完成了对 $( \pm)$-maoecrystal V 的全合成. 在合成过程中，他们发现，通过 IMDA 过程得到的中间体 143 经过转化而来的四环中间 体 145 的 C-5 位手性与 maoecrystal V 的 C-5 位的手性相 反. 于是他们先对 1,2 位双键进行环氧化, 接下来氧化 4 位的羟基, 转化为化合物 148 . 化合物 148 经过苯硫醇 的共轭加成、 $\mathrm{NaBH}_{4}$ 还原、 Raney-Ni 的脱硫作用、脱 水及去乙酰基保护得到关键中间体 150. C-5 位正确手性 的中间体 151 可以通过环氧化重排反应获得(Scheme 25). 拿到中间体 151 后, 关键就是在 $\mathrm{A}$ 环上引入 $\gamma$-二甲 基- $\alpha, \beta$-不饱和酮结构(Scheme 26).

\subsection{Zakarian 组对(-)-maoecrystal V 的全合成}

2014 年 Zakarian 组 ${ }^{[43]}$ 完成了对(一)-maoecrystal V 的对映选择性的全合成. 在他的合成工作中, $\mathrm{Rh}$ 催化的 $\mathrm{C}-\mathrm{H}$ 官能团化是对映选择性控制的步骤，得到 2,3-二 氢苯并呋喃中间体 $\mathbf{1 6 0}$. 在合成过程中，他们尝试了不 对称催化和使用手性助剂两种方法，但最后还是选择了 使用手性助剂. 其原因在于, 在后续合成中需要的多种 官能团存在的情况下，使用手性助剂具有更好的反应效 果. 通过构建 $\mathrm{Si}$ 连接的二环环系而发生的 IMDA 反应确 保了(+)-maoecrystal V 的绝对立体构型(Scheme 27).

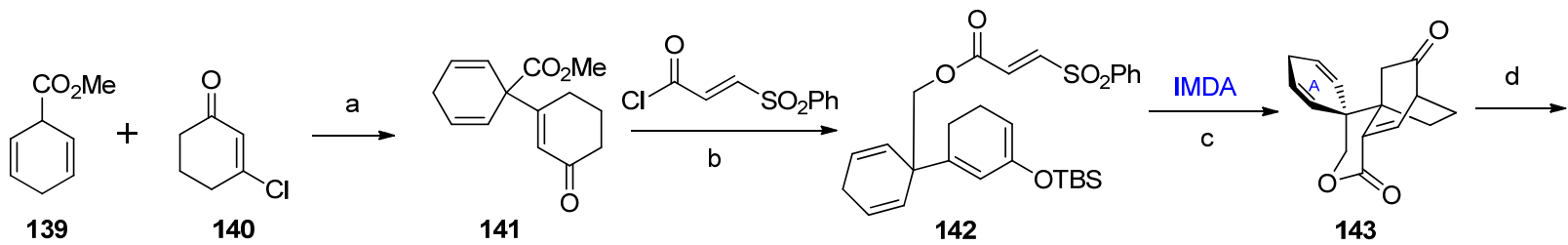<smiles>O=C(O)C1C(=O)CC2CCCC1CC2</smiles>
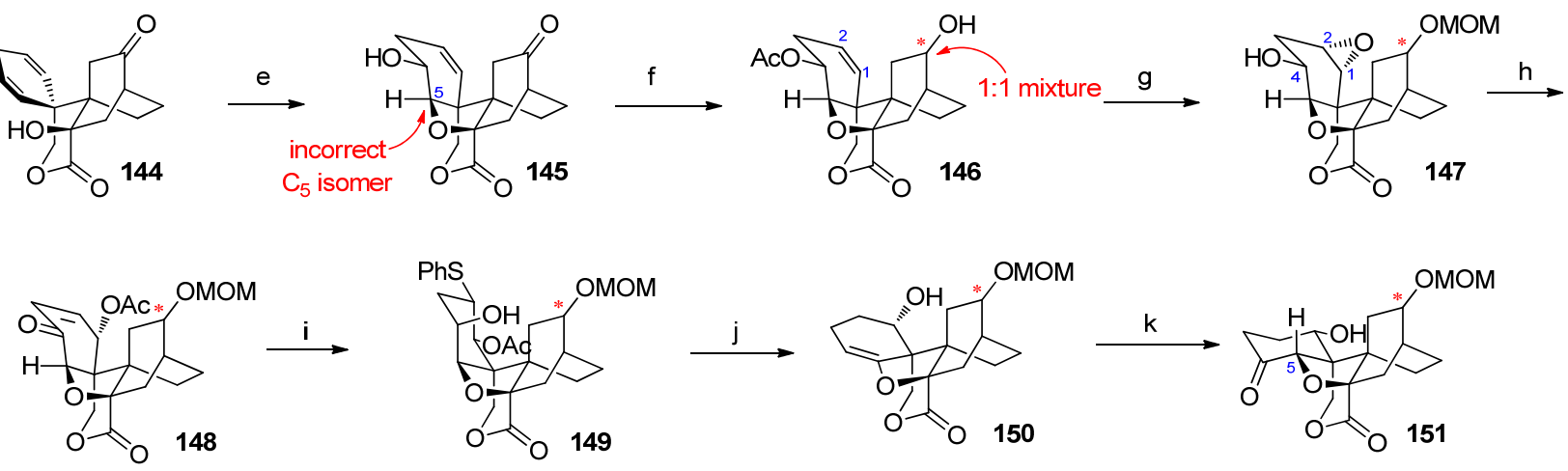

Reagents and conditions: (a) LDA, $-78{ }^{\circ} \mathrm{C}$, THF, $40 \%$. (b) (1) DIBAL-H, $-78{ }^{\circ} \mathrm{C}, \mathrm{CH}_{2} \mathrm{Cl}_{2}$; (2) $\mathrm{MnO}_{2}, \mathrm{CH}_{2} \mathrm{Cl}_{2}$, r.t.; (3) pyridine, $\mathrm{CH}_{2} \mathrm{Cl}_{2}, 0{ }^{\circ} \mathrm{C}$; (4) TBSOTf, TEA, $\mathrm{CH}_{2} \mathrm{Cl}_{2}, 53 \%$ overall. (c) toluene, sealed tube, then TBAF, THF, $62 \%$. (d) (1) $\mathrm{H}_{2} \mathrm{O}_{2}, \mathrm{NaOH}, \mathrm{MeOH}, 0^{\circ} \mathrm{C} ;(2) \mathrm{Mgl}_{2}, \mathrm{CH}_{2} \mathrm{Cl}_{2}, 45^{\circ} \mathrm{C}$; (3) $\mathrm{Bu}_{3} \mathrm{SnH}$, AlBN, toluene, reflux, $48 \%$ overall. (e) (1) $m$-CPBA, $\mathrm{CH}_{2} \mathrm{Cl}_{2}$, r.t.; (2) $p$ - $\mathrm{TsOH}_{2} \mathrm{O}, \mathrm{CH}_{2} \mathrm{Cl}_{2}$, r.t., $65 \%$. (f) (1) $\mathrm{Ac}_{2} \mathrm{O}$, pyridine, $\mathrm{CH}_{2} \mathrm{Cl}_{2}$; (2) $\mathrm{NaBH}_{4}, \mathrm{CH}_{2} \mathrm{Cl}_{2} / \mathrm{EtOH}, 85 \%$. (g) (1) MOMCl, $i-\mathrm{Pr}_{2} \mathrm{Net}$; (2) $\mathrm{K}_{2} \mathrm{CO}_{3}, \mathrm{MeOH}$; (3) $m$-CPBA, 86\% overall. (h) (1) DMP, $\mathrm{NaHCO}_{3}, \mathrm{CH}_{2} \mathrm{Cl}_{2}$; (2) $\mathrm{Ac}_{2} \mathrm{O}$, pyridine, $\mathrm{CH}_{2} \mathrm{Cl}_{2}, 77 \%$ in two steps. (i) $\mathrm{PhSH}, \mathrm{Et} \mathrm{N}_{3} \mathrm{~N}$; then $\mathrm{NaBH}_{4}, \mathrm{EtOH} / \mathrm{CH}_{2} \mathrm{Cl}_{2}, 78 \%$. (j) (1) Raney-Ni; (2) MsCl, DMAP; (3) $\mathrm{K}_{2} \mathrm{CO} 3, \mathrm{MeOH}, 62 \%$ overall. (k) DMDO; then $\mathrm{BF}_{3} \cdot \mathrm{Et}_{2} \mathrm{O}, 82 \%$

图式 25 Danishefsky 组对中间体 $\mathbf{1 5 1}$ 的合成

Scheme 25 Danishefsky's synthesis of intermediate 151 

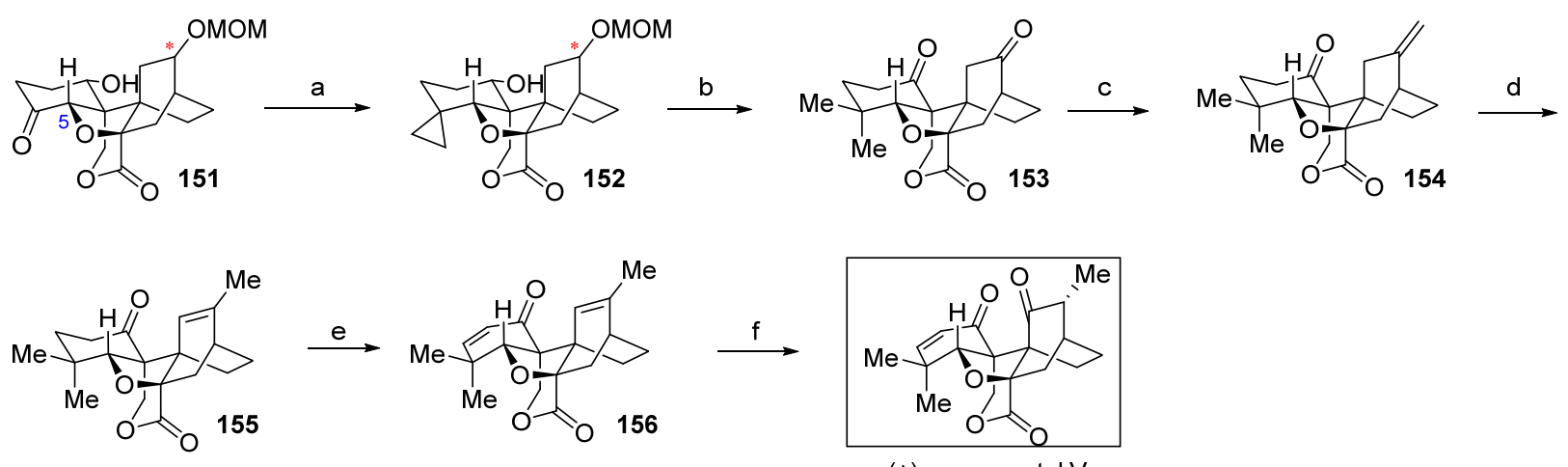

(士)-maoecrystal V

Reagents and conditions: (a) (1) Lombardo reagent, $\mathrm{CH}_{2} \mathrm{Cl}_{2}$; (2) $\mathrm{CH}_{2} \mathrm{I}_{2}, \mathrm{Zn} / \mathrm{Ag}$, Et $\mathrm{Et}_{2} \mathrm{O}$. (b) (1) $\mathrm{PCC}, \mathrm{CH}_{2} \mathrm{Cl}_{2}$; (2) $\mathrm{H}_{2}, \mathrm{PtO}$, AcOH. (c) Lombardo reagent, $\mathrm{CH}_{2} \mathrm{Cl}_{2}$. (d) $p$-TsOH $\bullet \mathrm{H}_{2} \mathrm{O}$, benzene. (e) LDA, TMSCl, THF; then $\mathrm{Pd}(\mathrm{TFA})_{2}, \mathrm{CH}_{3} \mathrm{CN}$. (f) (1) TFDO, $\mathrm{CH}_{2} \mathrm{Cl}_{2} ;(2) \mathrm{BF}_{3} \cdot \mathrm{Et}_{2} \mathrm{O}, \mathrm{CH}_{2} \mathrm{Cl}_{2}$

图式 26 Danishefsky 组的 $( \pm)$-maoecrystal V 合成工作

Scheme 26 Danishefsky's synthesis of $( \pm)$-maoecrystal V

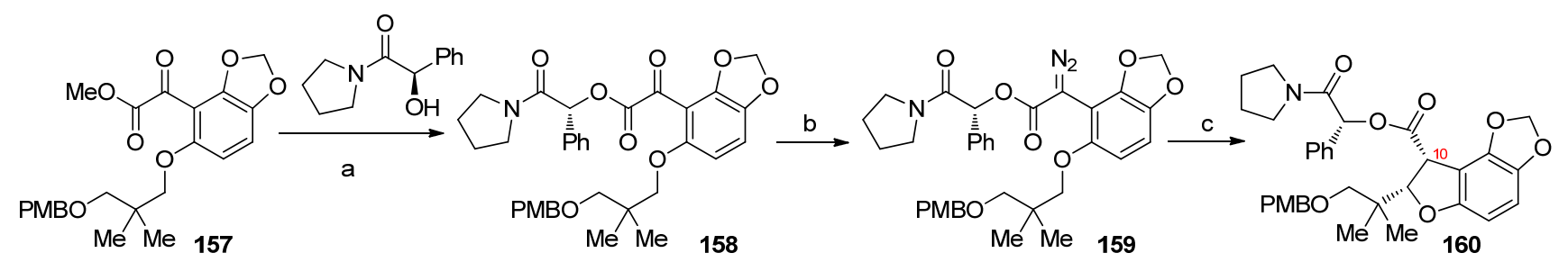

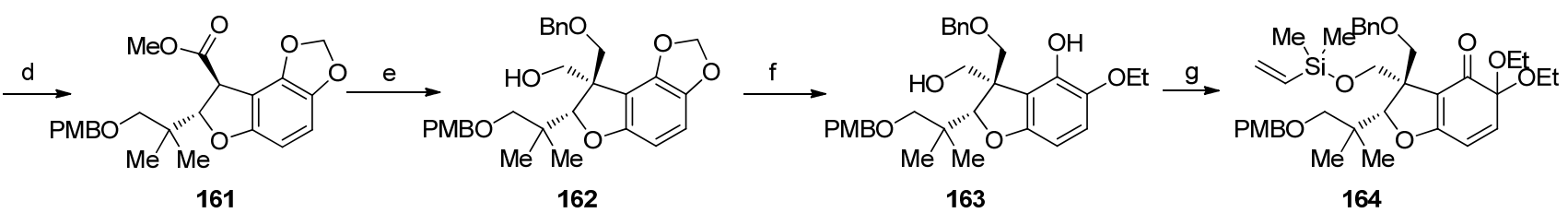

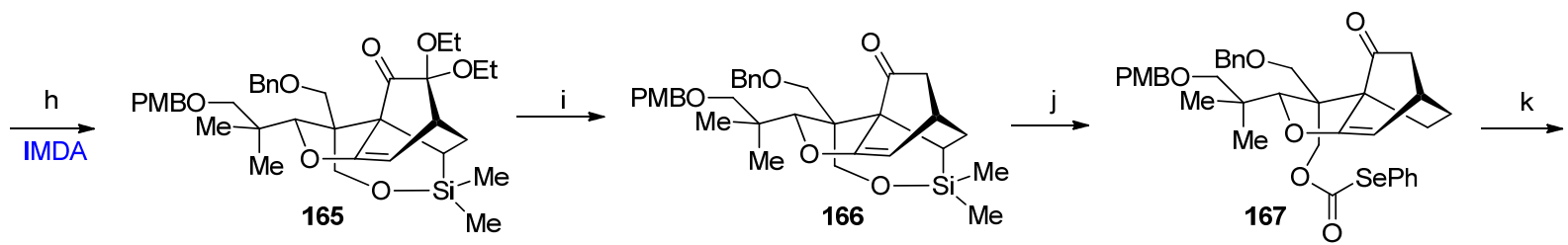

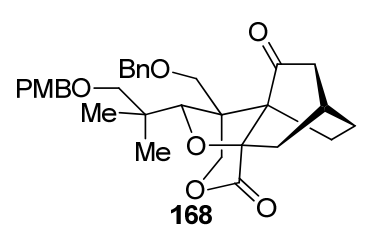
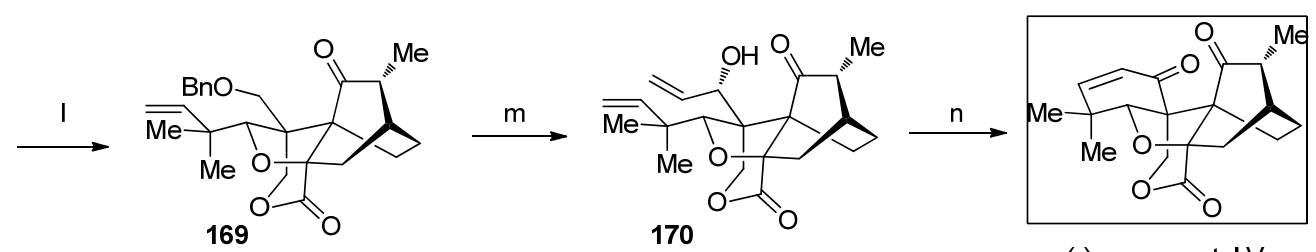

(-)-maoecrystal V

Reagents and conditions: (a) (1) $\mathrm{NaOH}$ (aq.), $\mathrm{MeOH}$; (2) $\mathrm{C}_{6} \mathrm{H}_{5} \mathrm{COCl}, \mathrm{Et}_{3} \mathrm{~N}$, toluene, 63\%. (b) (1) $\mathrm{TMSNHNH}_{2}, \mathrm{PhH}$; (2) $\mathrm{Et}_{3} \mathrm{~N}, \mathrm{CH}_{2} \mathrm{Cl}_{2}, 63 \%$. (c) 2 mol\% $\mathrm{Rh}_{2}(\mathrm{OAc})_{4}, 4 \AA \mathrm{MS}, \mathrm{CH}_{2} \mathrm{Cl}_{2}, 61 \%, 84 \%$ ee. (d) $\mathrm{CH}_{3} \mathrm{ONa}, \mathrm{CH}_{3} \mathrm{OH}, 84 \%$. (e) (1) LDA, THF; then $\mathrm{Et}_{2} \mathrm{Zn}, \mathrm{BnOCH}_{2} \mathrm{Cl}, \mathrm{DMPU}^{2}$ (2) $\mathrm{LiAlH}_{4}$, THF, $80 \%, d r>30$ : 1. (f) $\mathrm{CH}_{3} \mathrm{MgBr}, \mathrm{Et} t_{2} \mathrm{O}, \mathrm{PhH}, 91 \%$. (g) (1) $\mathrm{Phl}\left(\mathrm{O}_{2} \mathrm{CCF}_{(3}\right)_{2}, \mathrm{NaHCO}_{3}, \mathrm{EtOH}$; (2) $\mathrm{CH}_{2}=\mathrm{CHSi}(\mathrm{Me}){ }_{2} \mathrm{Cl}, \mathrm{ImH}, \mathrm{CH}_{2} \mathrm{Cl}_{2}, 87 \%$ in two steps. (h) toluene, $110{ }^{\circ} \mathrm{C}, 97 \%$. (i) $\mathrm{Sml}_{2}, \mathrm{MeOH}$, THF, r.t., 85\%. (j) (1) $\mathrm{Bu}_{4} \mathrm{NF}, \mathrm{DMPU}$; (2) $\mathrm{Im}_{2} \mathrm{CO}$, THF; (3) (PhSe) $2, \mathrm{NaBH}_{4}, \mathrm{DMF}$, about $40 \%$. (k) $\left(\mathrm{Me}_{2} \mathrm{Si}\right)_{3} \mathrm{SiH}, \mathrm{AIBN}, \mathrm{PhH}, 40 \% \sim 55 \%$. (I) (1) $\mathrm{DDQ}, \mathrm{CH}_{2} \mathrm{Cl}_{2} / \mathrm{H}_{2} \mathrm{O}$; (2) DMP, $\mathrm{CH}_{2} \mathrm{Cl}_{2}$; (3) $\mathrm{Ph}_{3} \mathrm{P}=\mathrm{CH}_{2}$, THF; (4) $\mathrm{LiN}\left(\mathrm{SiMe}_{3}\right)_{2}, \mathrm{CH}_{3} \mathrm{l}, \mathrm{THF}, 50 \%$, $d r=7$ : 1. (m) (1) DDQ, $\mathrm{CH}_{2} \mathrm{Cl}_{2} / \mathrm{H}_{2} \mathrm{O}$; (2) DMP, $\mathrm{CH}_{2} \mathrm{Cl}_{2}$; (3) $\mathrm{CH}_{2}=\mathrm{CHMgBr}, 65 \%, d r>10$ : 1. (n) (1) 20 mol\% Hoveyda-Grubbs II catalyst, $\left(\mathrm{CH}_{2} \mathrm{Cl}\right)_{2} ;(2) \mathrm{DMP}, \mathrm{CH}_{2} \mathrm{Cl}_{2}, 88 \%$

图式 27 Zakarian 组的(一)-maoecrystal V 合成工作

Scheme 27 Zakarian's synthesis of ( - -maoecrystal V

5.4 Thomson 组对(一)-maoecrystal $V$ 的全合成

2014 年 Thomson 小组 ${ }^{[44]}$ 也完成了对 $(-)$-maoe- crystal V 的对映选择性的全合成. 他们的合成是从 4,4二甲基环己烯酮 171 开始, 经历 Baylis-Hillman 反应 ${ }^{[45]}$ 
和 Shapeless 不对称环氧化反应合成化合物 172. 接下来 对化合物 172 与化合物 173 反应后经环氧的还原转化为 烯丙醇结构化合物 174. 使用 TESCl 保护的化合物 174 在 $\mathrm{Pd}\left(\mathrm{Ph}_{3} \mathrm{P}\right)_{4}$ 的作用下生成 2,3-位的烯烃机构 176, 同时 也会生成少量的 1,2-位烯烃 175.176 去芳构化后的产物 二烯酮 177 的 13,14-位双键还原后在 TMSCl 作用下形 成烯醇梄 179, 179 与硝基乙烯发生 Diels-Alder 反应形成 环加成产物 180. 经一系列转化得到 15-位是羰基的化 合物 181 后，在 16-位引入甲基并发生脱硫反应得到化 合物 182. 经过烯丙基溴中间体的氧化, 得到烯酮 183 . 最后, 经过 C-20 位选择性氧化得到目标分子 (一)-maoecrystal V (Scheme 28).

\section{5 洪然组对( \pm -cafestol 的合成}

Cafestol 是二萜衍生物, 洪然小组 ${ }^{[46]}$ 提出这一分子 可能是通过对映-贝壳杉烯的 C-18 位和 C-19 位的甲基 迁移反应及 $\mathrm{A}$ 环 C-3 位和 C-4 位并入呋喃环获得, 并于 近期完成了对其全合成工作.

他们课题组的合成策略是先通过 Aldehyde-Ene 引 发的环化反应立体选择性的构建 $\mathrm{A} / \mathrm{B} / \mathrm{C}$ 三环体系 186, 通过对反应条件的篎选, 最终能以很好的选择性生成
186 (cis/trans $<1 / 20$, paralortho $=8 / 1$, 分离产率 $73 \%$ ). 再经过 Birch 还原反应对 C 环去芳构化及 Luche 还原反 应转化为烯丙醇 188. 对于 C-8 位四级碳的引入使用的 是 Eschenmoser-Claisen 重排反应，中性反应条件对此步 反应是至关重要的，因为这样可以减少脱水副反应的发 生. 再经过碘介导的酯化反应和碱促进的消除反应得到 双键迁移的内酯 190. 190 经 DIBAL-H 还原为内半缩醛 后经 $\mathrm{SmI}_{2}$ 介导的自由基环化反应得到二醇 191 (Scheme 29).

由于 $\mathrm{C}-14$ 位和 $\mathrm{C}-16$ 位羟基的不同化学环境，可以 实现对 C-16 位的选择性氧化, 进而通过Wittig 成烯反应 和 Barton-McCombie 自由基脱氧作用构建二环[3.2.1]辛 烷 193. 脱除 TBS 保护基团后氧化生成的环酮，在 LiHMDS 和 Vedejs 试剂( $\left.\mathrm{MoO}_{5}(\mathrm{py})(\mathrm{HMPA})\right)$ 作用下发生 羟基化反应转化为 194. 在 C-4 位立体选择性引入炔基 后通过 $\mathrm{Akai}^{\mathrm{i}}{ }^{[7]}$ 发展的方法构建呋喃环. 但在这一底物 上, 经过 $\mathrm{Au}$ 催化的呋喃环形成反应在复杂的底物上温 和高效的引入敏感的呋喃环. 通过使用 $\mathrm{OsO}_{4}$ 对 $\mathrm{D}$ 环环 外双键进行双羟基化反应得到 $( \pm)$-Cafestol（Scheme 30).

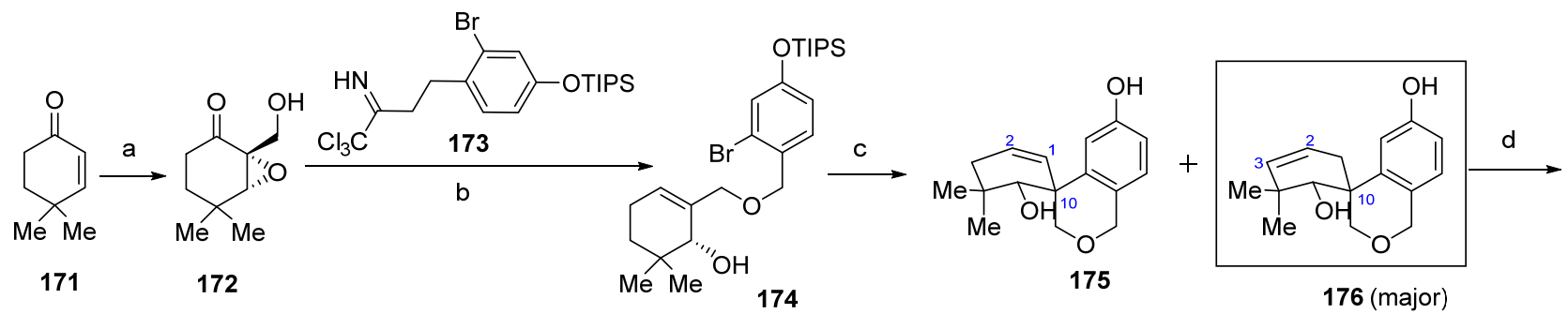

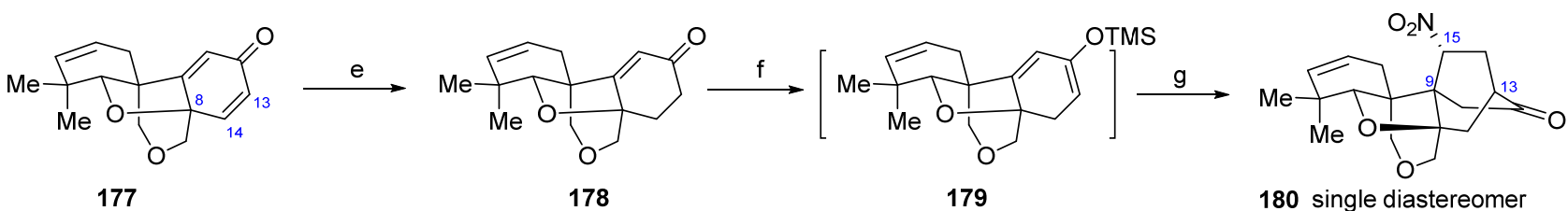

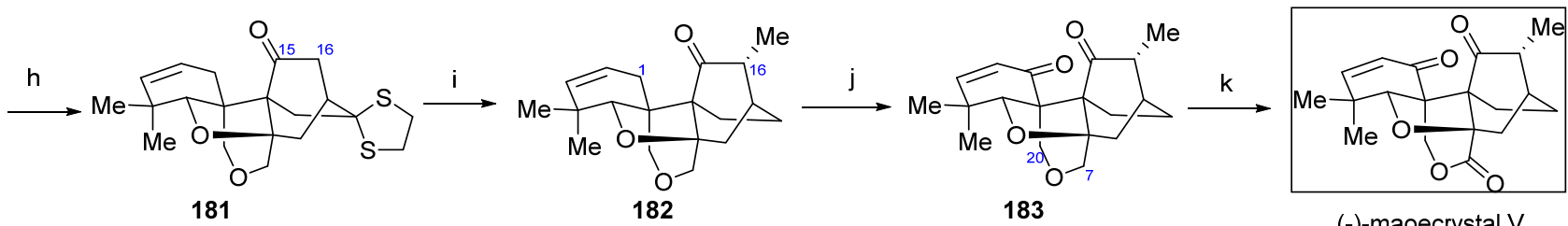

Reagents and conditions: (a) (1) $\mathrm{CH}_{2} \mathrm{O}$, sodium docecyl sulfate, DMAP, $\mathrm{H}_{2} \mathrm{O}$; (2) (-)-diisopropyltartrate, Ti(i-PrO) $)_{4}, t$ - $\mathrm{BuOOH}, 4 \AA \mathrm{MS}, 53 \%$ in two steps, $94 \%$ ee. (b) 1) TfOH, 173; (2) $\mathrm{NaBH}_{4}$; (3) $\mathrm{Ph}_{3} \mathrm{P}, \mathrm{I}_{2}$, imidazole; (4) $\mathrm{Zn}, \mathrm{NH}_{4} \mathrm{Cl}, 61 \%$ overall. (c) (1) $\mathrm{TESCl}$, imidazole; (2) $\mathrm{Pd}\left(\mathrm{Ph}_{3} \mathrm{P}\right)_{4}$ PMP; then TBAF, $52 \%$ of 176. (d) Phl(OAc) $)_{2} \mathrm{NaHCO}_{3},\left(\mathrm{CF}_{3}\right)_{2} \mathrm{CHOH} / \mathrm{CH}_{2} \mathrm{Cl}_{2}, 95 \%$. (e) Stryker's catalyst, $\mathrm{PhSiH}$, 92\%. (f) LDA, TMSCl. (g) $\mathrm{CH}_{2}=\mathrm{CHNO}_{2}, \mathrm{BHT}, \mathrm{PhH}$; then $\mathrm{HCl} / \mathrm{THF}, 55 \%$. (h) (1) 1,2-ethanedithiol, $\mathrm{BF}_{3} \cdot \mathrm{Et}_{2} \mathrm{O}$; then $\mathrm{Zn} / \mathrm{HCl}$; (2) IBX, DMSO; $1 \mathrm{~mol} / \mathrm{L} \mathrm{HCl}, 78 \%$ in two steps. (i) (1) $\mathrm{K}_{2} \mathrm{CO}_{3},\left(\mathrm{CH}_{2} \mathrm{O}\right)_{n}, \mathrm{DMF}$; (2) $\mathrm{NaBH}_{4}, \mathrm{MeOH}$; then Raney Ni, 94\%, dr>15 : 1. (j) NBS, benzoylperoxide, $\mathrm{CCl}_{4}$, then $\mathrm{AgBF}_{4}, \mathrm{DMSO}, 73 \%$ (k) $\mathrm{CrO}_{3} / \mathrm{AcOH}, \mathrm{CH}_{2} \mathrm{Cl}_{2}, 28 \%$

图式 28 Thomson 组的(一)-maoecrystal V 合成工作

Scheme 28 Thomson's synthesis of $(-)$-maoecrystal V 

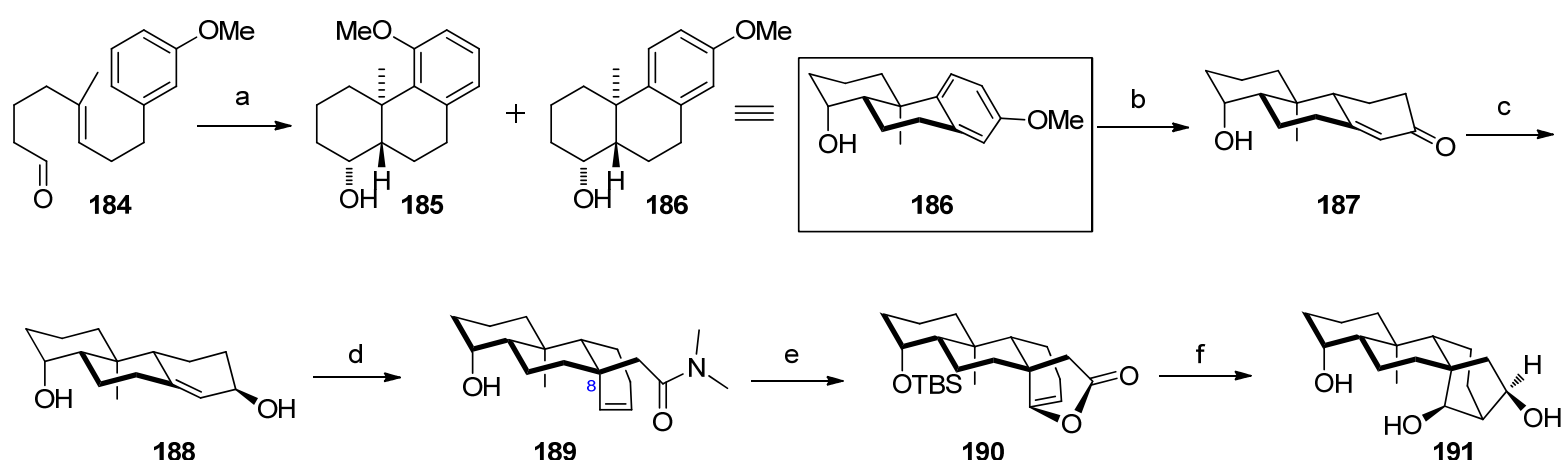

Reagents and conditions: (a) $\mathrm{Me}_{3} \mathrm{Al},-78{ }^{\circ} \mathrm{C}, \mathrm{CH}_{2} \mathrm{Cl}_{2}, 46 \%$ (cis/trans $<1 / 20,186: 185>20$ : 1). (b) (1) $\mathrm{Li}, \mathrm{NH}_{3}(\mathrm{l}), \mathrm{THF}, t$ - $\mathrm{BuOH}$; (2) $\mathrm{HCl}$ (aq.), $78 \%$. (c) $\mathrm{NaBH}_{4}, \mathrm{CeCl}_{3} \cdot 7 \mathrm{H}_{2} \mathrm{O}, \mathrm{MeOH}, 73 \%$ (ds=9: 1). (d) $\mathrm{DMA}$, xylene, $160{ }^{\circ} \mathrm{C}, 72 \%$. (e) (1) $\mathrm{I}_{2}, \mathrm{THF} / \mathrm{H}_{2} \mathrm{O}$; (2) DBU, THF; (3) TBSOTf, 2,6-lutidine, DMF, $85 \%$ overall. (f) (1) $i-\mathrm{Bu}_{2} \mathrm{AlH}, \mathrm{CH}_{2} \mathrm{Cl}_{2}$; (2) $\mathrm{Sml}_{2}, \mathrm{HMPA},-40{ }^{\circ} \mathrm{C}$; (3) $\mathrm{HF}$ (aq. $40 \%$ ), $\mathrm{CH}_{3} \mathrm{CN}, 75 \%$ overall

图式 29 洪然对中间体 192 的合成

Scheme 29 Hong's synthesis of intermediate 192

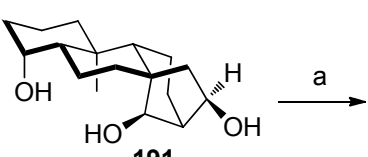

191

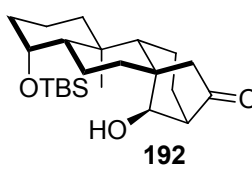

192

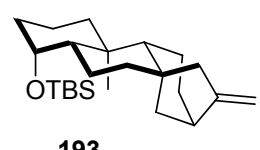

193

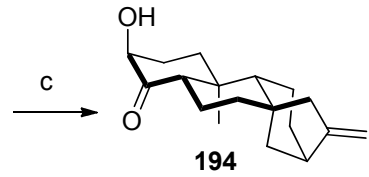

194

(土)-cafestol

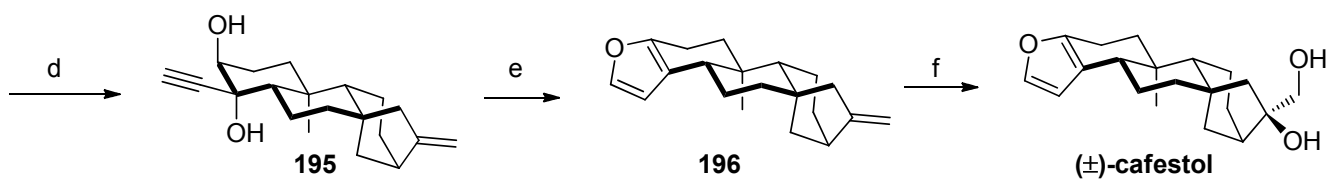

Reagents and conditions: (a) DMP, $\mathrm{NaHCO}_{3}, \mathrm{CH}_{2} \mathrm{Cl}_{2}, 96 \%$ (based recover starting material) (b) (1) $\mathrm{Ph}_{3} \mathrm{PCH}_{3} \mathrm{Br}, t$ - $\mathrm{BuOK}$, toluene; (2) $\mathrm{CS}_{2}$, $\mathrm{NaH}$, imidazole, Mel; (3) $\mathrm{Bu}_{3} \mathrm{SnH}$, AlBN, toluene, $64 \%$ overall. (c) (1) TBAF, THF; (2) DMP, $\mathrm{NaHCO}_{3}, \mathrm{CH}_{2} \mathrm{Cl}_{2}$; (3) $\mathrm{LiHMDS}, \mathrm{MoOPH}, 67 \%$. (d) $\mathrm{HC} \equiv \mathrm{CMgBr}$, THF, 96\% (ds $>30: 1$ ). (e) $\mathrm{Ph}_{3} \mathrm{PAuCl}, \mathrm{AgBF}_{4}, \mathrm{CH}_{2} \mathrm{Cl}_{2}, 93 \%$. (f) OsO $\mathrm{O}_{4}$, pyridine, THF; then $\mathrm{Na}_{2} \mathrm{SO}_{3}, \mathrm{H}_{2} \mathrm{O} / \mathrm{Et}_{2} \mathrm{O}, 75 \%$

图式 30 洪然组的 $( \pm)$-Cafestol 合成工作

Scheme 30 Hong's synthesis of $( \pm)$-cafestol

\section{6 总结与展望}

综上所述，对映-贝壳杉烷型二萜分子的合成方法 多种多样, 很多优秀的方法学被发掘出来并应用到这类 分子的合成中, 具有很强的原创性和启发性. 随着分离 技术和鉴定手段的长足发展, 越来越多的对映一贝壳杉 烷型二萜分子被分离得到. 这些分子中有很大一部分的 生物活性还不清楚, 只靠分离得到的样品相当有限, 很 难满足生物学实验的需求, 因此, 发展经济、高效的全 合成路线, 特别是通过一个中间体实现多个分子的集体 全合成的课题摆在我们面前, 有待进一步研究.

\section{References}

[1] Sun, H.-D.; Huang, S.-X.; H, Q.-B. Nat. Prod. Rep. 2006, 23, 673.

[2] (a) Kubo, I.; Xu, Y.-L.; Shimizu, K. Phytother. Res. 2004, 18, 180. (b) Kadota, S.; Basnet, P.; Ishii, E.; Tamura, T.; Namba, T. Zentralbl. Bakteriol. 1997, 286, 63.

[3] Arai, T.; Koyama, Y.; Morita. T.; Kaji, H. Chemotherapy (Tokyo) 1961, 9, 403.

[4] Hayashi, K.; Hayashi, T.; Sun, H.-D.; Takeda, Y. Cancer Gene Ther. 2000, 7, 45 .
[5] Bohlmann, J.; Meyer-Gauen, G.; Croteau, R. Proc. Natl. Acad. Sci. U. S. A. 1998, 95, 4126.

[6] Turner, R. B.; Ganshirt, K. H.; Shaw, P. E.; Tauber, J. D. J. Am. Chem. Soc. 1966, 88, 1776.

[7] Church, R. F.; Ireland, T. E.; Marshall, J. A. J. Org. Chem. 1966, $31,2526$.

[8] Duc, D. K. M.; Fetizon, M.; Lazare, S. J. Chem. Soc., Chem. Commun. 1975, 282.

[9] Duc, D. K. M.; Fetizon, M.; Lazare, S. Tetrahedron 1978, 34, 1207.

[10] Ireland, R. E.; Mander, L. M. Tetrahedron Lett. 1965, 30, 2627.

[11] Bell, R. A.; Ireland, R. E.; Partyka, R. A. J. Org. Chem. 1962, 27, 3741.

[12] (a) Masamune, S. J. Am. Chem. Soc. 1964, 86, 288. (b) Masamune, S. J. Am. Chem. Soc. 1964, 86, 289.

[13] Monti, S. A.; Yang, Y.-L. J. Org. Chem. 1979, 44, 897.

[14] (a) Mori, K.; Matsui, M. Tetrahedron 1966, 22, 879.

(b) Mori, K.; Nakahara, Y.; Matsui, M. Tetrahedron Lett. 1970, 28, 2411.

(c) Mori, K.; Nakahara, Y.; Matsui, M. Tetrahedron 1972, 28, 3217.

[15] Barltrop, J. A.; Day, A. C. J. Chem. Soc. 1959, 671.

[16] Cook, I. F.; Knox, J. R. Tetrahedron Lett. 1970, 47, 4091.

[17] Ziegler, F. E.; Kloek, J. A. Tetrahedron 1977, 33, 373.

[18] Snider, B. B. Chem. Rev. 1996, 96, 339.

[19] Snider, B. B.; Kiselgof, J. Y.; Foxman, B. M. J. Org. Chem. 1998, 63,7945 . 
[20] Cherney, E. C.; Green, J. C.; Baran, P. S. Angew. Chem., Int. Ed. 2013, 52, 9019 .

[21] Hoffmann, R. W. Elements of Synthesis Planning, Spring, Berlin, 2009, pp. 106 117 .

[22] ApSimon, J. The Total Synthesis of Natural Products, Vol. 8, John Wiley \& Sons, Inc., Ottawa, 1992, pp. 101 128 .

[23] Kende, A. S.; Sanfilippo, P. J. Synth. Commun. 1983, 13, 715.

[24] (a) Mori, K.; Matsui, M. Tetrahedron Lett. 1966, 2, 175. (b) Mori, K.; Matsui, M. Tetrahedron 1968, 24, 3095.

[25] Mori, K.; Matsui, M. Tetrahedron Lett. 1970, 37, 3287.

[26] Kametani, T.; Suzuki, K.; Nemoto, H.; Fukumoto, K. J. Org. Chem. 1979, 44, 1036.

[27] Kashiwada, Y.; Nishizawa, M.; Yamagishi, T.; Tanaka, T.; Nanaka, G. L.; Cosentino, L. M.; Snider, J. V.; Lee, K. H. J. Nat. Prod. 1995, 58,392 .

[28] (a) Chen, K.; Shi, Q.; Fujioka, T.; Zhang, D.-C.; Hu, C.-Q.; Jin, J.-Q.; Kilkuskie, R. E.; Lee, K. H. J. Nat. Prod. 1992, 55, 88.

(b) Chen, K.; Shi, Q.; Fujioka, T.; Nakano, T.; Hu, C.-Q.; Jin, J.-Q.; Kilkuskie, R. E.; Lee, K.-H. Bioorg. Med. Chem. 1995, 3, 1345.

[29] Corey, E. J.; Liu, K. J. Am. Chem. Soc. 1997, 119, 9929.

[30] Arai, T.; Koyama, Y.; Morita, T.; Kaji, H. Chemotherapy (Tokyo) 1961, 9, 403.

[31] Litake, Y.; Natsume, M. Acta Crystallogr. 1966, $20,197$.

[32] Fujita, E.; Shibuya, M.; Nakamura, S.; Okada, Y.; Fujita, T. J. Chem. Soc., Perkin Trans. 1 1974, 165.

[33] Kenny, M. J.; Mander, L. N.; Sethi, S. P. Tetrahedron Lett. 1986, $27,3927$.
[34] Han, Q.-B.; Cheung, S.; Tai, J.; Qiao, C.-F.; Song, J.-Z.; Tso, T.-F.; Sun, H.-D.; Xu, H.-X. Org. Lett. 2006, 8, 4727.

[35] Cha, J. Y.; Yeoman, J. T. S.; Reisman, S. E. J. Am. Chem. Soc. 2011, 133, 14964

[36] Yeoman, J. T. S.; Mak, V. W.; Reisman, S. E. J. Am. Chem. Soc. 2013, 135, 11764.

[37] (a) Paquette, L. A.; Ladouceur, G. J. Org. Chem. 1989, 54, 4278. (b) Ladouceur, G.; Paquette, L. A. Synthesis 1992, 185.

[38] Paquette, L. A.; Backhaus, D.; Braun, R.; Underiner, T. L.; Fuchs, K. J. Am. Chem. Soc. 1997, 119, 9662.

[39] Li, S.-H.; Wang, J.; Niu, X.-M.; Shen, Y.-H.; Zhang, H.- J.; Sun, H.-D.; Li, M.-L.; Tian, Q.-E.; Lu, Y.; Cao, P.; Zheng, Q.-T. Org. Lett. 2004, 6, 4327.

[40] Gong, J.-X.; Lin, G.; Sun, W.-B.; Li, C.-C.; Yang, Z. J. Am. Chem. Soc. 2010, 132, 16745.

[41] Gong, J.-X.; Lin, G.; Li, C.-C.; Yang, Z. Org. Lett. 2009, 11, 4770.

[42] Peng, F.; Danishefsky, S. J. J. Am. Chem. Soc. 2012, 134, 18860.

[43] Lu, P.; Mailyan, A.; Gu, Z.-H.; Guptill, D. M.; Wang, H.-B.; Davies, H. M. L.; Zakarian, A. J. Am. Chem. Soc. 2014, 136, 17738.

[44] Zheng, C.-W.; Dubovyk, I.; Lazarski, K. E.; Thomson, R. J. J. Am. Chem. Soc. 2014, 136, 17750

[45] Porzelle, A.; Williams, C. M.; Schwartz, B. D.; Gentle, I. R. Synlett 2005, 2923.

[46] Zhu, L.-L.; Luo, J.-H.; Hong, R. Org. Lett. 2014, 16, 2162.

[47] (a) Egi, M.; Azechi, K.; Akai, S. Org. Lett. 2009, 11, 5002. (b) Aponick, A.; Li, C.-Y.; Malinge, J.; Marques, E. F. Org. Lett. 2009, 11, 4624 . 